\title{
NLRP3 regulates a non-canonical platform for caspase-8 activation during epithelial cell apoptosis
}

\author{
H Chung ${ }^{1,3}$, A Vilaysane ${ }^{1,3}$, A Lau ${ }^{1}$, M Stahl ${ }^{2}$, V Morampudi ${ }^{2}$, A Bondzi-Simpson ${ }^{1}$, JM Platnich ${ }^{1}$, NA Bracey ${ }^{1}$, M-C French ${ }^{1}$, PL Beck ${ }^{1}$, \\ $\mathrm{J} \mathrm{Chun}^{1}$, BA Vallance ${ }^{2}$ and DA Muruve ${ }^{*, 1}$
}

Nod-like receptor, pyrin containing 3 (NLRP3) is characterized primarily as a canonical caspase-1 activating inflammasome in macrophages. NLRP3 is also expressed in the epithelium of the kidney and gut; however, its function remains largely undefined. Primary mouse tubular epithelial cells (TEC) lacking Nlrp3 displayed reduced apoptosis downstream of the tumor necrosis factor (TNF) receptor and CD95. TECs were identified as type II apoptotic cells that activated caspase-8, tBid and mitochondrial apoptosis via caspase-9, responses that were reduced in NIrp3 - / - cells. The activation of caspase-8 during extrinsic apoptosis induced by TNF $\alpha /$ cycloheximide (TNF $\alpha / C H X)$ was dependent on adaptor protein apoptosis-associated speck-like protein containing a CARD (ASC) and completely independent of caspase-1 or caspase-11. TECs and primary human proximal tubular epithelial cells (HPTC) did not activate a canonical inflammasome, caspase-1, or IL-1 $\beta$ secretion in response to TNF $\alpha / C H X$ or NLRP3-dependent triggers, such as ATP or nigericin. In cell fractionation studies and by confocal microscopy, NLRP3 colocalized with ASC and caspase-8 in speck-like complexes at the mitochondria during apoptosis. The formation of NLRP3/ASC/caspase-8 specks in response to TNF $\alpha /$ CHX was downstream of TNFR signaling and dependent on potassium efflux. Epithelial ASC specks were present in enteroids undergoing apoptosis and in the injured tubules of wild-type but not NIrp3-/- or ASC - / - mice following ureteric unilateral obstruction in vivo. These data show that NLRP3 and ASC form a conserved non-canonical platform for caspase-8 activation, independent of the inflammasome that regulates apoptosis within epithelial cells.

Cell Death and Differentiation (2016) 23, 1331-1346; doi:10.1038/cdd.2016.14; published online 19 February 2016

Nod-like receptor, pyrin containing 3 (NLRP3) is an innate sensor that has been characterized primarily as an inflammasome-forming protein in leukocytes. ${ }^{1}$ NLRP3 is activated by a wide range of pathogen/danger-associated molecular patterns to regulate host cellular responses to infection and injury. ${ }^{1}$ In the canonical pathway, NLRP3 activation triggers the oligomerization of the adaptor protein apoptosisassociated speck-like protein containing a CARD (ASC) and caspase-1 into a high molecular weight inflammasome that regulates cytokine maturation (IL-1 $\beta$ and IL-18) and pyroptosis. $^{2}$ Emerging studies have demonstrated non-canonical NLRP3 inflammasomes that activate alternate caspases such as caspase- 8 and caspase-11 in leukocytes and more recently caspase $4 / 11$ in the intestinal epithelium. ${ }^{3-5}$

Caspase- 8 is an initiator caspase in the apoptosis pathway activated downstream of death receptors such as tumor necrosis factor receptor (TNFR) and CD95. In type I apoptotic cells, caspase-8 is recruited to the death-inducing signaling complex (DISC) at the plasma membrane where it undergoes autocleavage and acts directly upon the executioner caspase-3 to initiate apoptosis. ${ }^{6}$ In type II apoptotic cells, caspase-8 activation at the DISC is inhibited by the caspase-3 inhibitor $x$-linked inhibitor of apoptosis (XIAP) and cellular FLICE inhibitory protein (cFLIP). ${ }^{6-8}$ Type II cells require the mitochondrial pathway to fully initiate the cell death program via caspase- 8 activation at the outer mitochondrial membrane that cleaves Bid to tBid. ${ }^{9}$ tBid triggers the oligomerization of Bax/Bak, which initiates mitochondrial outer membrane permeabilization, cytochrome $c$ release and activation of caspase-9. ${ }^{6}, 10$ Initiation of mitochondrial apoptosis also releases SMAC/DIABLO, which inhibits XIAP and enables caspase-3 to further activate caspase- $8 .^{11}$

Caspase- 8 is also activated downstream of the NLRP3, AIM2 and NLRC4 inflammasomes in response to canonical triggers in macrophages ${ }^{4,12-14}$ or downstream of Dectin-1 in dendritic cells. ${ }^{15-17}$ The activation of caspase-8 in leukocytes requires ASC and regulates the non-canonical maturation of $\mathrm{IL}-1 \beta$. However in caspase-1/11-deficient macrophages, caspase-8 also regulates apoptosis downstream of AIM2 and NLRP3 inflammasomes. ${ }^{4,12}$ The relationship between NLRP3, ASC and caspase- 8 activation during apoptosis in the absence of inflammasome activation or in a physiological caspase-1deficient system has not yet been evaluated.

Epithelial cells have key roles in tissue homeostasis, host defense, immune regulation and regeneration. In the kidney,

\footnotetext{
${ }^{1}$ Department of Medicine, Snyder Institute for Chronic Diseases, University of Calgary, Calgary, AB, Canada and ${ }^{2}$ Department of Pediatrics, Child and Family Research Institute, University of British Columbia, Vancouver, BC, Canada

*Corresponding author: DA Muruve, Department of Medicine, Snyder Institute for Chronic Diseases, University of Calgary, 3280 Hospital Drive NW, Calgary, AB T2N 4Z6, Canada. Tel: +1 403220 2418; Fax: +1 403210 3949; E-mail: dmuruve@ucalgary.ca

${ }^{3}$ These authors contributed equally to this work.

Abbreviations: ASC, apoptosis-associated speck-like protein containing a CARD; BMDM, bone marrow-derived macrophages; CHX, cycloheximide; cFLIP, cellular FLICE inhibitory protein; DISC, death-inducing signaling complex; FLICA, FAM-LETD-fmk or FAM-YVAD-fmk; HPTC, primary human proximal tubular epithelial cells; LPS, lipopolysaccharide; MSU, monosodium urate crystals; MTT, 3-(4, 5-dimethylthiazol-2-yl)-2, 5-diphenyltetrazolium bromide; NLRP3, Nod-like receptor, pyrin containing 3; TEC, primary mouse tubular epithelial cells; TNFR, tumor necrosis factor receptor; UUO, unilateral ureteric obstruction; XIAP, x-linked inhibitor of apoptosis Received 18.6.15; revised 30.12.15; accepted 20.1.16; Edited by M Deshmukh; published online 19.2.16
} 
a

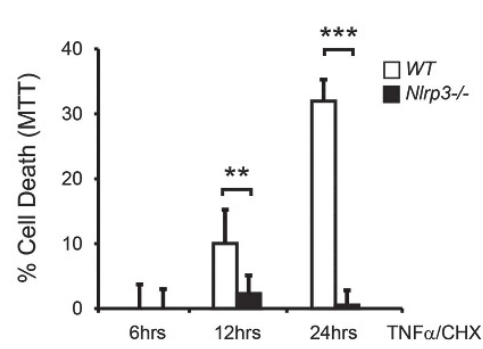

C

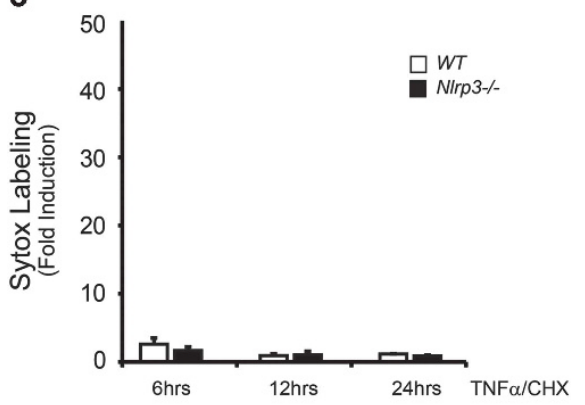

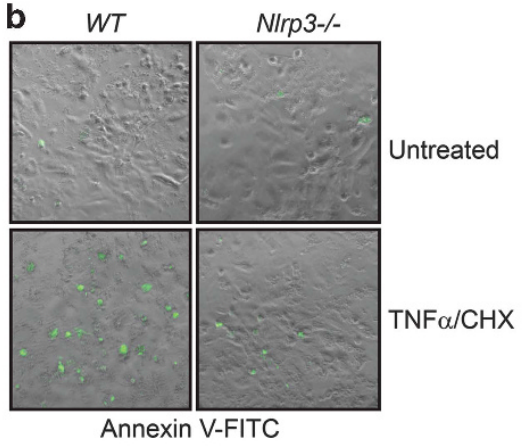

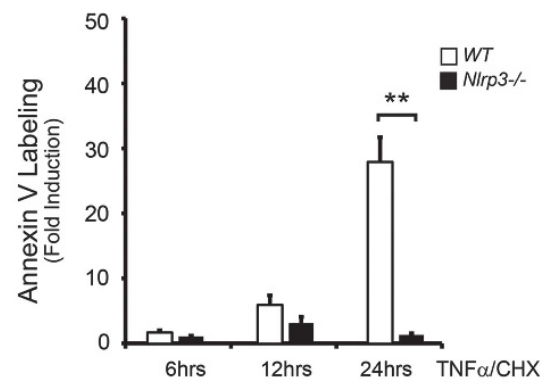

Figure 1 Role of NIrp3 in tubular epithelial cell apoptosis. (a) Cell viability (MTT) assay at 6, 12 and $24 \mathrm{~h}$ in wild-type (WT) or N/rp3-/ - TECs treated with TNF $\alpha$ (10 ng/ml) and $\mathrm{CHX}\left(5 \mu \mathrm{g} / \mathrm{ml}\right.$ ) (mean \pm S.E.M.; WT versus Nlrp3 - / $,{ }^{* *} P<0.01, n=3$ independent experiments). (b) Annexin V immunofluorescence of TECs treated with TNF $\alpha / \mathrm{CHX}$. Images are shown as a brightfield and FITC channel overlay ( $\times 10$ lens, $\times 3$ zoom). Right panel quantitation of Annexin V positivity in WTor NIrp3 - / TECs treated with TNF $\alpha$ / $\mathrm{CHX}$ at 6,12 and 24 h. (mean \pm S.E.M.; WT versus NIrp3 $-/{ }^{* \star} P<0.01,{ }^{* * *} P<0.001, n=3$ independent experiments). (c) Sytox orange labeling in WT and Nlrp3 $-/-$ TECs treated with TNF $\alpha / \mathrm{CHX}$ at 6,12 and $24 \mathrm{~h}$. (d) Immunoblotting using antibodies specific for caspase-3 (pro-p32 and cleaved p17), total PARP1 and cleaved PARP1 (cPARP1) in WT and NIrp3-/- TECs induced to undergo apoptosis with TNF $\alpha / \mathrm{CHX}$ for 6, 12 and $24 \mathrm{~h}$

tubular epithelial cell apoptosis is a major component of disease that contributes to tubular atrophy and tubulointerstitial fibrosis. ${ }^{18}$ The intestinal epithelium lies at the hostmicrobial interface and is key to maintaining gut homeostasis as well as directing the host response to the gut microbiota and to pathogenic microbes. Inflammasome genes such as NLRP3 and ASC are expressed in both gut and kidney epithelia. ${ }^{3,19-21}$ We and others have demonstrated primarily non-canonical and inflammasome-independent roles for NLRP3 in the kidney epithelium and during experimental kidney injury in vivo. ${ }^{20-23}$ For example, NIrp3-/- mice undergoing renal ischemia/reperfusion or unilateral ureteric obstruction (UUO) display reduced epithelial apoptosis and tubular injury independent of a canonical inflammasome or caspase-1. ${ }^{20-23}$ In the intestinal tract, non-canonical NLRP3 regulates IL-18 maturation as well as epithelial cell shedding in response to Salmonella infection. ${ }^{3}$ Despite these studies, the biology of NLRP3 and other inflammasomerelated genes in epithelial cells has yet to be fully elucidated.

Given the increasing evidence of crosstalk between the inflammasome and cell death machinery in the cell, the role of NLRP3 in epithelial cell apoptosis was determined. We show that NLRP3, via ASC, primarily regulates a noncanonical caspase-8-activating platform at the mitochondria that is necessary for epithelial cell death. The activation of caspase- 8 by NLRP3 in epithelia occurs independent of canonical NLRP3 triggers, caspase-1, or pro-inflammatory cytokine production.

\section{Results}

NIrp3 is required for apoptosis and caspase-8 activation in epithelial cells. To examine the involvement of NIrp3 in receptor-mediated epithelial cell apoptosis, primary mouse tubular epithelial cells (TEC) were treated with tumor necrosis factor-a/cycloheximide (TNFa/CHX) and probed using Annexin $V$ and assessed for viability using the 3-(4, 5-dimethylthiazol-2yl)-2, 5-diphenyltetrazolium bromide (MTT) assay. At $24 \mathrm{~h}$, NIrp3-/- TECs displayed significantly less cell death as well as reduced surface labeling with Annexin $\mathrm{V}$ compared with control wild-type controls (Figures 1a and b). Cell death was due to apoptosis as minimal Sytox orange labeling was observed following TNFa/CHX stimulation over $24 \mathrm{~h}$ (Figure 1c, Supplementary Figure S1). NIrp3-/- TECs also displayed significantly reduced caspase-3 activation and cleavage of its substrate poly-ADP-ribose polymerase (PARP1) (Figure 1d). Together, these results show that NIrp3-/- TECs exhibit reduced cell death and apoptosis induced by TNFa/CHX.

$\mathrm{TNFa} / \mathrm{CHX}$ also induced cleavage of caspase-8 at $24 \mathrm{~h}$ in TEC, a response that was significantly diminished in Nirp3-/- cells (Figure 2a). To determine whether NIrp3 was also required for apoptosis involving the SMAC-dependent/RIP1 pathway ${ }^{24}$ or CD95, TECs were stimulated with TNF $a$ and the SMAC-mimetic birinapant ${ }^{25}$ or an activating CD95 antibody (Jo2). Over $24 \mathrm{~h}$, both TNFa/birinapant and anti-CD95 resulted in efficient apoptosis and caspase- 8 and 
a

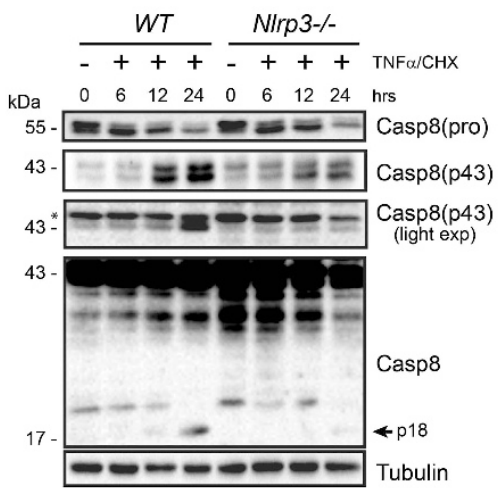

b

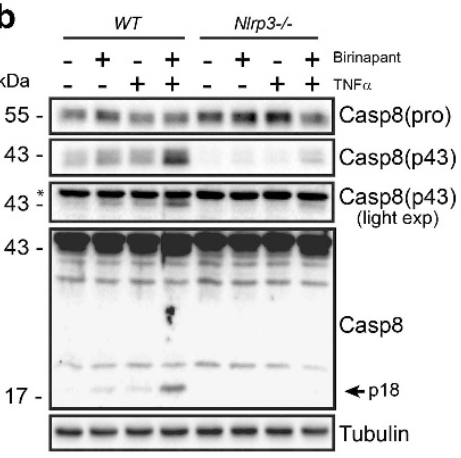

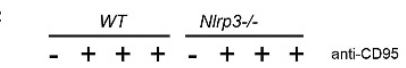

$\begin{array}{llllllllll}\mathrm{kDa} & 0 & 6 & 12 & 24 & 0 & 6 & 12 & 24 & \mathrm{hrs}\end{array}$

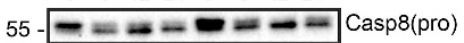

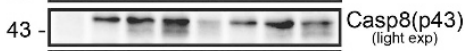

43

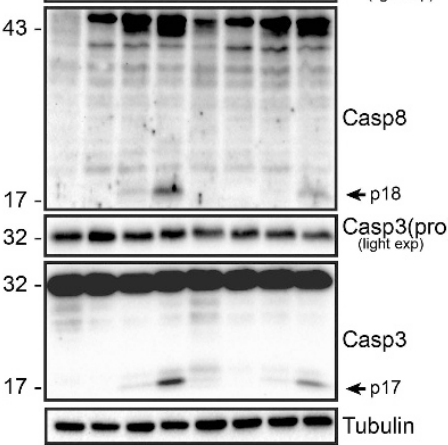

d

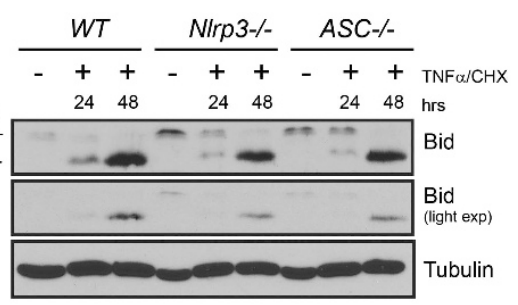

e

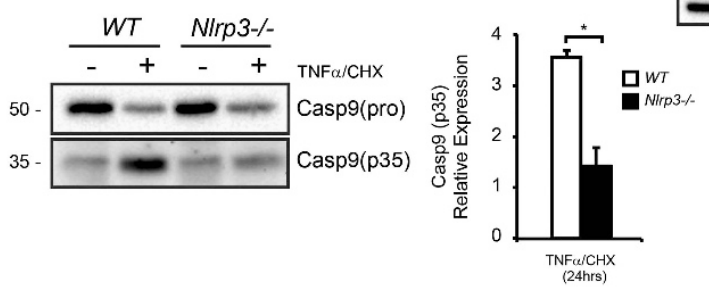

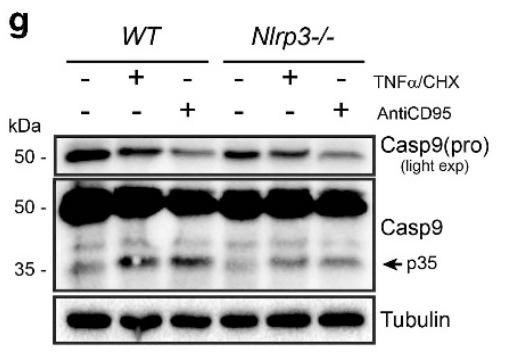

h

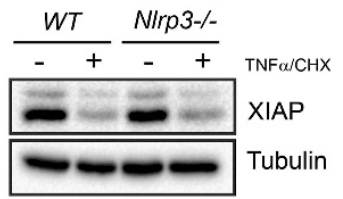

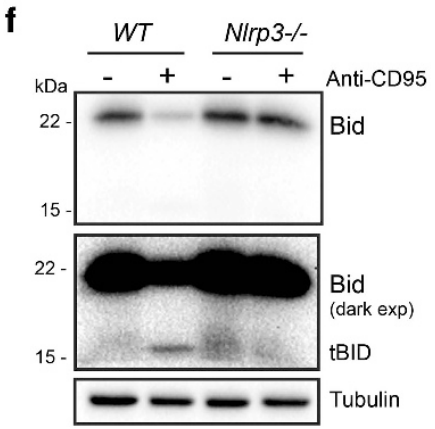

Figure 2 Nlrp3-dependent regulation of death receptor-mediated apoptosis. (a) TECs were incubated for the indicated time points with TNF $\alpha$ (10 ng $/ \mathrm{ml})$ and CHX (5 $\mu \mathrm{g} / \mathrm{ml})$. Immunoblotting using antibodies specific for caspase-8 (pro), caspase-8 (p41/43) and caspase-8 (p41/43, p18) in wild-type (WT) and N/rp3 - / - TECs. Asterisk represents nonspecific band. (b) Immunoblotting for caspase-8 in WT and NIrp3 - / - TECs treated for the indicated times with TNF $\alpha(10 \mathrm{ng} / \mathrm{ml})$ and the SMAC-mimetic birinapant (10 $\mu \mathrm{M})$. (c) Immunoblotting for caspase-8 and caspase-3 in WT and NIrp3-/ - TECs treated for the indicated times with the activating CD95 antibody (Jo2). (d) Immunoblotting for fulllength (22 kDa) and cleaved Bid (15 kDa) in WT and NIrp3-/- and ASC-/- TECs after TNF $\alpha / C H X$ treatment at 24 and $48 \mathrm{~h}$. (e) Immunoblotting for pro-caspase-9 and cleaved caspase-9 (p35) in TECs stimulated with TNF $\alpha / C H X$. Quantification of caspase-9 normalized to $\beta$-tubulin (mean \pm S.D.; TNF $\alpha / C H X 24$ h, WT versus NIrp3-/-, ${ }^{*} P<0.05, n=3$ independent experiments). (f) Immunoblotting for full-length (22 kDa) and cleaved Bid (15 kDa) in WT and Nirp3-/- TECs after CD95 activation at $24 \mathrm{~h}$. (g) Immunoblotting for caspase-9 (pro-p50 and cleaved p35 subunit) in TECs stimulated with TNF $\alpha / C H X$ and CD95 activating antibody at $24 \mathrm{~h}$. (h) Immunoblotting for XIAP protein in TNF $\alpha / \mathrm{CHX}$-treated WT and N/rp3-/- TECs at $24 \mathrm{~h}$

caspase-3 activation in wild-type TEC, responses that were significantly impaired in NIrp3-/- cells (Figures $2 b$ and $c$ and Supplementary Figures S2a-c and S3b). Together, these data show that NIrp3 is required for caspase-8 activation and apoptosis downstream of the TNFR and CD95.

Caspase-8 activation and cell death emerged over 12-24 h, suggesting that TECs represent type II apoptotic cells (Figures $2 \mathrm{a}-\mathrm{C}$ and Supplementary Figure S2d). Consistent with this premise, TNFa/CHX- and CD95-treated TECs effectively cleaved Bid to truncated Bid (tBid) and activated caspase-9 (Figures $2 \mathrm{~d}-\mathrm{g}$ ), responses that were significantly reduced in NIrp3-/- cells. Consistent with their type II cell death phenotype, wild-type and NIrp3-/- TECs express similar levels of DISC genes, including not only TRADD, FADD, TRAF2 and RIP1 (Supplementary Figure S3a) but also the apoptosis inhibitors XIAP and cFLIP (Figure 2h,Supplementary Figure S3a). Furthermore, the SMAC-mimetic birinapant also enhanced CD95-induced apoptosis that was attenuated in NIrp3-/- TECs (Supplementary Figure S3b). In contrast, peritoneal macrophages are type I apoptotic cells that display similar levels of caspase8 activation in N/rp3-/- and wild-type cells following receptor-mediated cell death as previously described (Supplementary Figure S4a). ${ }^{26}$ TECs assumed a type I phenotype and NIrp3 became dispensable for apoptosis when TNFR and CD95 activation were combined with both 
birinapant and $\mathrm{CHX}$ to antagonize multiple inhibitory pathways (Supplementary Figure S4b). Finally, fractionation studies were performed comparing primary human proximal tubular epithelial cells (HPTC) and human THP-1 macrophages. In response to $\mathrm{TNFa} / \mathrm{CHX}$, cytochrome $c$ release in the cytoplasm was observed in HPTC but not in THP-1 cells at $24 \mathrm{~h}$ (Figure 6a). Together, these data show that Nirp3 regulates receptor-mediated caspase-8 activation and apoptosis in TECs (type II cells) but not in macrophages (type I cells).

Role of the inflammasome in NIrp3-mediated caspase-8 activation in TEC. Experiments were next performed to determine whether the regulation of caspase-8 was downstream of the Nlrp3 inflammasome. The activation of the Nirp3 inflammasome using the canonical agonist nigericin in bone marrow-derived macrophages (BMDM) results in the activation of both caspase- 1 and caspase- 8 as previously reported $^{4,13}$ (Supplementary Figure S5). In the absence of caspase-1 or caspase-11, caspase- 8 activation by nigericin is maintained confirming that caspase- 8 is a downstream effector of the NIrp3 inflammasome. Mouse TECs express both NIrp3 and $\mathrm{ASC}^{21}$ but compared with BMDM very little caspase-1 as detected by immunoblotting (Figure $3 a$ ). In contrast, caspase-11 is expressed in both BMDM and TEC and, as expected, is absent in caspase-1/11-/- cells. Caspase-1 was not induced in TECs by TNFa or lipopolysaccharide (LPS); however, NIrp3 was modestly increased by both stimuli (Supplementary Figures S6a and b). Given these data, the possibility existed that, in the absence of caspase-1, NIrp3 may regulate apoptosis in TECs through the formation of a non-canonical inflammasome involving caspase-8 and/or caspase-11. As caspase-8 has been shown to interact with ASC via its pyrin domain, ${ }^{4}$ experiments were performed in ASC-/- TEC. In response to TNFa/CHX, ASC-/- TECs displayed reduced apoptosis, caspase-8 and caspase-3 activation as well as Bid cleavage compared with wild-type cells (Figures $2 \mathrm{~d}$ and $3 \mathrm{~b}, \mathrm{~d}$ and $\mathrm{e}$ and Supplementary Figure S1). In contrast, caspase-1 and caspase-11 were dispensable as caspase- 8 and caspase- 3 activation was intact in caspase-1/11-/- TECs (Figures 3c-e and Supplementary Figure S1) and TNFa/CHX did not induce caspase-11 cleavage in wild-type or NIrp3-/- TECs at 24 and $48 \mathrm{~h}$ (Supplementary Figure S6c). Together, these results exclude caspase- 1 and caspase-11 downstream of NIrp3 in the regulation of caspase-8 in TEC. Rather, these observations suggest that caspase- 8 activation may occur through a non-canonical inflammasome involving NIrp3 and ASC.

Experiments were next performed to evaluate the effect of canonical NLRP3 agonists in TEC. The treatment of LPS-primed TECs with adenosine triphosphate (ATP), monosodium urate crystals (MSU) or nigericin failed to activate caspase-8 (Figure 3f). Similarly, none of the canonical NIrp3 agonists induced IL-1 $\beta$ or IL-18 secretion from TEC, unlike the robust cytokine maturation induced by ATP in BMDM (Figure 3g, Supplementary Figure S6d). Cytokine secretion in TECs was also absent following TNFa/CHX treatment, excluding IL-1 $\beta$ or IL-18 in the regulation of caspase- 8 by NIrp3. In HPTC that express both caspase-1 and caspase-8, ATP or nigericin failed to activate an inflammasome as demonstrated by caspase- 1 or -8 cleavage (Figure $3 \mathrm{~h}$ ). In contrast, THP-1 macrophages process caspase-1 and -8 efficiently in response to nigericin, and HPTC activate caspase- 8 but not caspase-1 cleavage in response to TNFa/CHX (Figure 3h). LPS or TNFa priming had little-to-no effect on caspase-1 or NLRP3 expression levels in HPTC or the ability to respond to canonical NIrp3 agonists (Supplementary Figure S6e). Thus mouse and human kidney epithelial cells do not readily form canonical inflammasomes or respond to canonical NLRP3 stimuli. Rather, these data suggest that NLRP3 may regulate a non-canonical apoptotic pathway in epithelial cells via ASC and caspase-8.

NIrp3-dependent caspase-8 activation occurs at the mitochondria. Confocal fluorescence microscopy was used to explore the relationship between NIrp3, ASC and caspase8 in tubular epithelial cells. Studies were performed in HPTC as antibodies for NIrp3, in our hands, perform poorly for immunofluorescence microscopy in TEC. Similar to reports in macrophages and cardiac fibroblasts, ${ }^{27-29}$ NLRP3 localized primarily to mitochondria in unstimulated HPTC (Figure 4a). There was no shift in NLRP3 localization between control and TNFa/CHX-stimulated cells, although 'speck-like' NLRP3-positive aggregates at the mitochondria could be observed following treatment. ASC was expressed diffusely and did not localize to mitochondria in HPTC at baseline. Following TNFa/CHX stimulation, ASC specks became visible that co-localized to mitochondria and with NLRP3 (Figures $4 \mathrm{~b}$ and $\mathrm{c}$ and Supplementary Figure S7a). Unlike macrophages where usually a single ASC speck per cell is formed during inflammasome activation, one to multiple ASC specks per cell could be observed in HPTC undergoing apoptosis. The co-localization of NLRP3 and ASC to mitochondria was specific as isotype controls were negative and no co-staining was observed with the Golgi marker GM130 or the lysosome marker LAMP1 at baseline or following stimulation with $\mathrm{TNFa} / \mathrm{CHX}$ (Supplementary Figure S7b-d). Furthermore, the formation of ASC specks were confirmed to be occurring in E-cadherin-positive epithelial cells (Supplementary Figure S7e).

Next, to determine the relationship of activated caspase-8 to NLRP3 and ASC specks, a fluorescent-labeled caspase-8 probe FAM-LETD-fmk (FLICA) was employed. Following stimulation with $\mathrm{TNF} a / \mathrm{CHX}$, a sizable pool of activated caspase- 8 but not caspase-1 was detected that co-localized to mitochondria in speck-like structures (Figure 5a, Supplementary Figure S8). Furthermore, NLRP3 and ASC co-localized with caspase-8 within specks in apoptotic HPTC (Figures 5b-d). NLRP3, ASC and caspase-8 also co-localized in HPTC following activation of CD95 (Supplementary Figure S9a). Furthermore, the specificity of ASC/caspase-8 specks were confirmed in $A S C-/-$ mouse TECs that demonstrate minimal caspase-8 activation and no ASC staining or speck formation in contrast to wild-type TECs treated with $\mathrm{TNF} a / \mathrm{CHX}$ (Supplementary Figure S9b). In comparison, and consistent with the type I phenotype, TNFa/CHX induced active caspase-8 THP-1 macrophages that did not co-localize to NLRP3, ASC or mitochondria (Supplementary Figures $\mathrm{S10a}$ and b). Furthermore, no NLRP3 or ASC specks could be observed in 
a

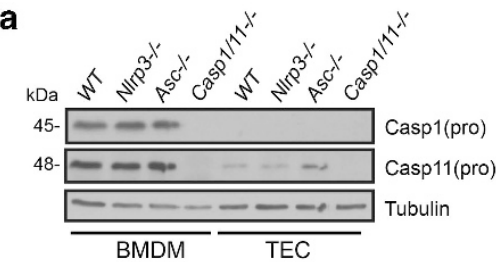

d

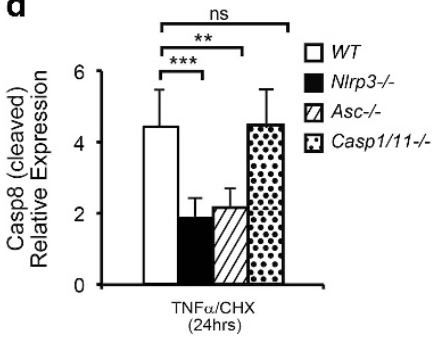

。

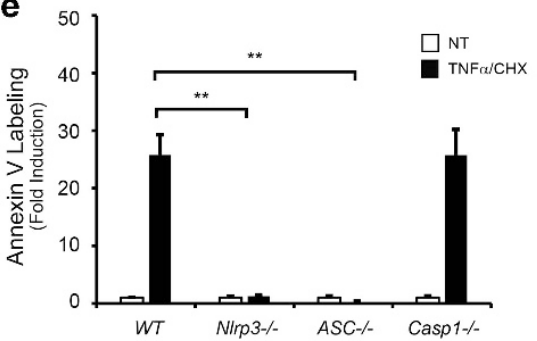

b

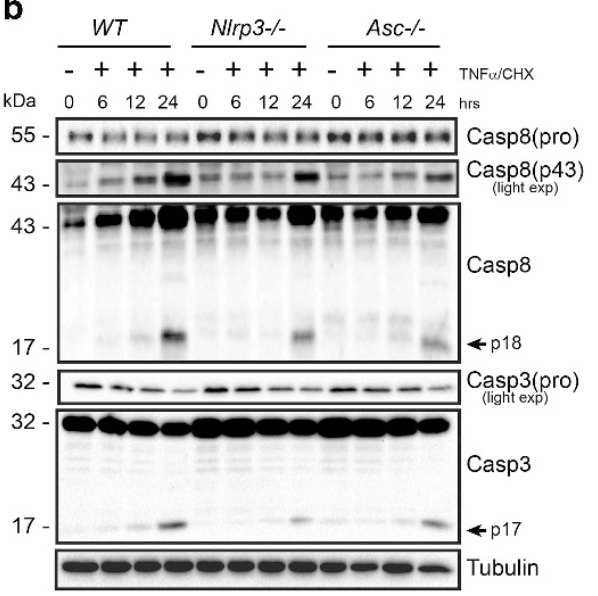

f

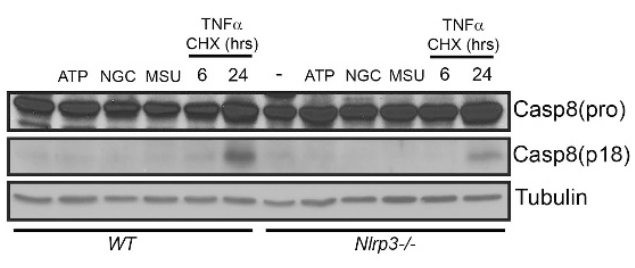

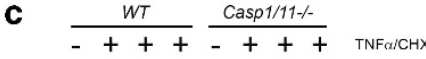

$\begin{array}{llllllllll}\mathrm{kDa} & 0 & 6 & 12 & 24 & 0 & 6 & 12 & 24 & \mathrm{hrs}\end{array}$

$55-\quad=-=-=-1$ Casp8(pro)

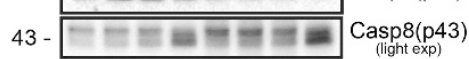

43 - EDDODO

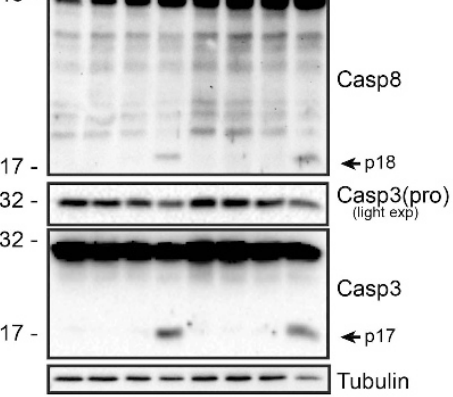

g

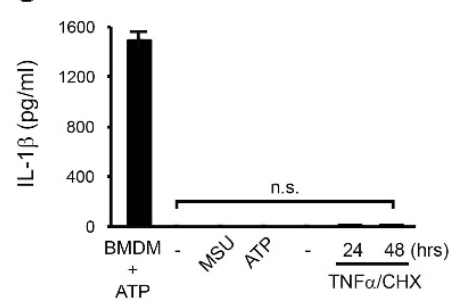

h

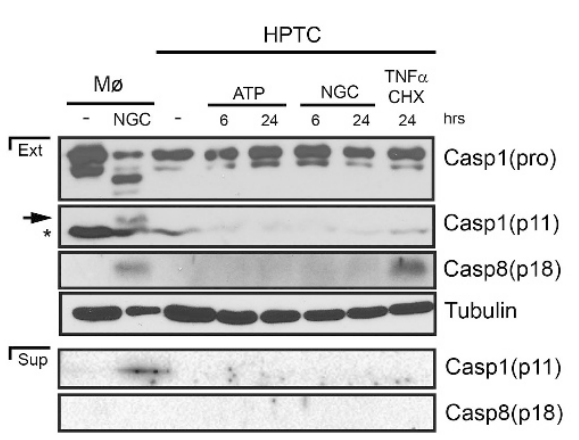

Figure 3 Role of the inflammasome in NIrp3-mediated caspase-8 activation. (a) Immunoblotting for pro-caspase-1 and pro-caspase-11 in wild-type (WT), NIrp3-/-, ASC - / - and casp1/11 - / - BMDMs and TECs. (b) Immunoblotting for caspase-8 (using antibodies specific for pro, p41/43 and p41/43/p18 forms) and caspase-3 in WT, NIrp3-/ - and ASC - / - TECs treated with TNF $\alpha(10 \mathrm{ng} / \mathrm{ml}) / \mathrm{CHX}(5 \mu \mathrm{g} / \mathrm{ml})$ at 6, 12 and $24 \mathrm{~h}$. (c) Immunoblotting for caspase-8 and caspase-3 in WT and casp $1 / 11-/-$ TECs treated with TNF $\alpha / C H X$. (d) Quantification of cleaved caspase-8 (p18) normalized to $\beta$-tubulin in WT, Nlrp3-/-, ASC $-/-$ and casp1/11 - / - TECs at $24 \mathrm{~h}$ (mean \pm S.D.; WT versus NIrp3 $-/-{ }^{* * *} P<0.001$ or $A S C-/-{ }^{* *} P<0.01$; WT versus Casp1/11-/ $-P=N S ; n=6$ independent experiments). (e) Annexin V staining in WT, NIrp3-/ , ASC $-/-$ and casp1/11-/- TECs treated with TNF $\alpha / C H X$ at $24 \mathrm{~h}$ (mean \pm S.E.M.; WT versus Nirp3-/- or ASC $-/-$, ${ }^{\star *} P<0.01$; WT versus Casp1/11-/-, $P=$ NS, $n=3$ independent experiments). (f) Immunoblotting for pro-caspase-8 and cleaved caspase-8 (p18) in LPS-primed WT and NIrp3-/- TECs treated for $6 \mathrm{~h}$ with

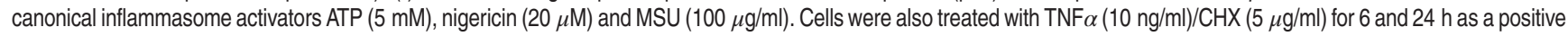
control. (g) IL-1 $\beta$ ELISA on WT TECs supernatants after treatment with MSU $(100 \mu \mathrm{g} / \mathrm{ml})$ and ATP $(5 \mathrm{mM})$ for $24 \mathrm{~h}$ and TNF $\alpha / \mathrm{CHX}$ for 24 and $48 \mathrm{~h}$. LPS-primed BMDM treated with ATP ( $5 \mathrm{mM}$ ) for $1 \mathrm{~h}$ was used as a positive control. (h) Immunoblotting for pro-caspase-1, cleaved caspase-1 (p11 N-terminal CARD, denoted by arrow. Asterisk is nonspecific band) and cleaved caspase-8 in LPS-primed HPTCs extracts and supernatants treated with ATP ( $5 \mathrm{mM})$, nigericin (20 $\mu \mathrm{M})$ and TNF $\alpha(10 \mathrm{ng} / \mathrm{ml}) / \mathrm{CHX}(25 \mathrm{ug} / \mathrm{ml})$ for the indicated time points. THP-1 cells treated with $20 \mu \mathrm{M}$ nigericin for $3 \mathrm{~h}$ were utilized as positive controls

THP-1 macrophages undergoing apoptosis (Supplementary Figure S10a). Conversely, the canonical NLRP3 agonist nigericin failed to induce caspase-8 activation, NLRP3 or ASC speck formation in both LPS-primed and unprimed HPTC (Supplementary Figure S11). Together, these results show that death-receptor mediated apoptosis triggers an NLRP3/ ASC/caspase-8 complex at the mitochondria in tubular epithelial cells but not in macrophages.
To corroborate the microscopy results, cellular fractionation studies demonstrated significant NLRP3 localization to the mitochondria at baseline in HPTC although significant cytosolic expression was also present (Figures 6a and b). These observations were in stark contrast to the primarily cytoplasmic NLRP3 localization in THP-1 macrophages (Figure 6a). A substantial reduction in the 110-kDa NLRP3 protein occurred in both cellular compartments following 
a

DAPI

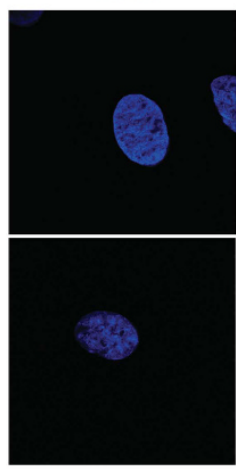

b
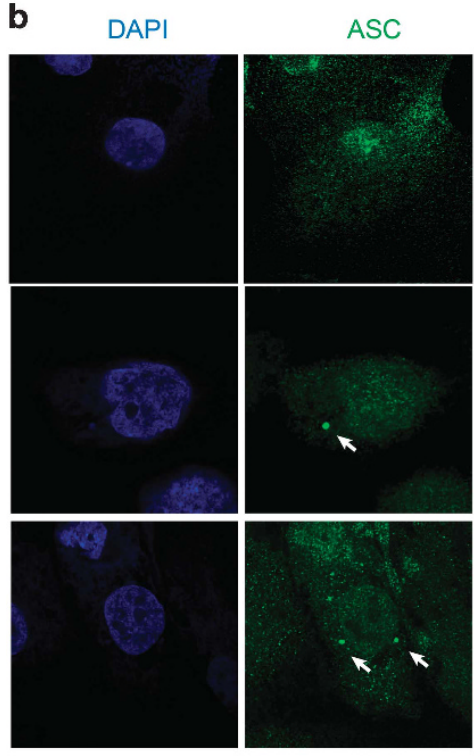

c
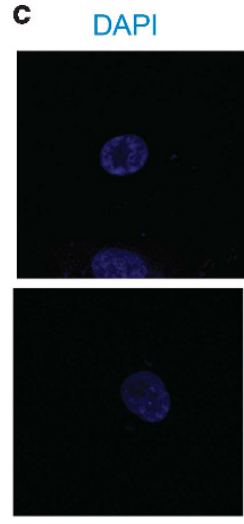

NLRP3
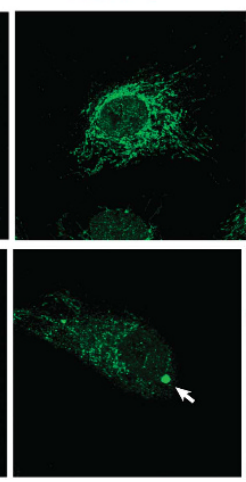

Figure 4 Co-localization of NLRP3 and ASC to mitochondria. Immunofluorescence confocal microscopy. (a) Untreated and TNF $\alpha(10 \mathrm{ng} / \mathrm{ml}) / \mathrm{CHX}(25 \mu \mathrm{g} / \mathrm{ml})$-treated HPTC at $24 \mathrm{~h}$ probing for NLRP3 (green) and mitochondria (Mitotracker Red). (b) ASC (green) and mitochondria (Mitotracker Red) in untreated and TNF $\alpha / \mathrm{CHX}$-treated HPTC (24 h). Arrows denote ASC co-localization to Mitotracker Red. (c) NLRP3 (green) and ASC (red) co-localization in TNF $\alpha$ /CHX-treated HPTC (24 h). Arrows denote ASC and NLRP3 colocalization. All cells were background stained with DAPI (blue) (all $\times 60$ lens, $\times 3$ zoom)

$\mathrm{TNFa} / \mathrm{CHX}$ stimulation, likely owing to formation of large molecular weight oligomers (Figures $6 a$ and $b$ and Supplementary Figure S12). In contrast to NLRP3, ASC and pro-caspase- 8 were restricted primarily to the cytoplasm in unstimulated HPTC. Following $\mathrm{TNFa} / \mathrm{CHX}$ stimulation, cleaved caspase-8 became enriched in the mitochondrial fraction (Figure 6b). Although the majority of ASC remained cytosolic, ASC monomers and ASC dimers became detectable at the mitochondria in the uncrosslinked and the disuccinimidyl suberate crosslinked fractions, respectively, 
a
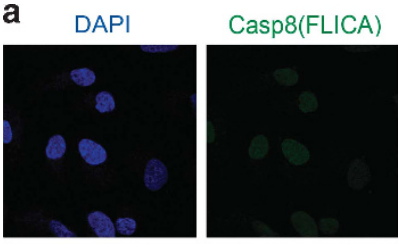

Mitotracker
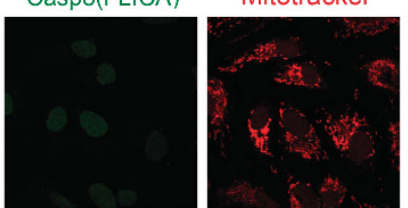

Merge
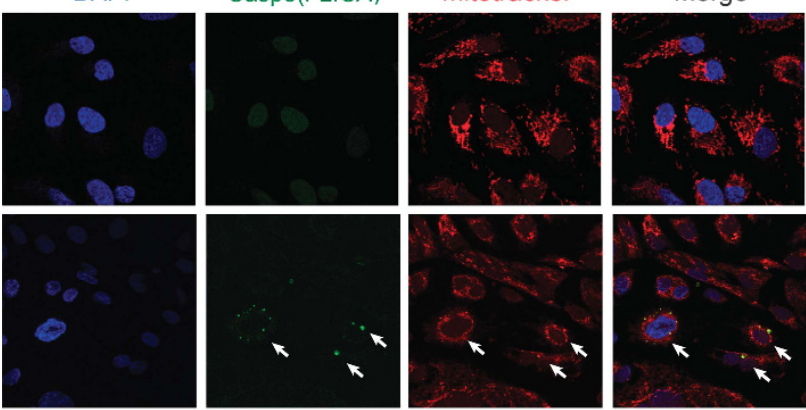

Untreated
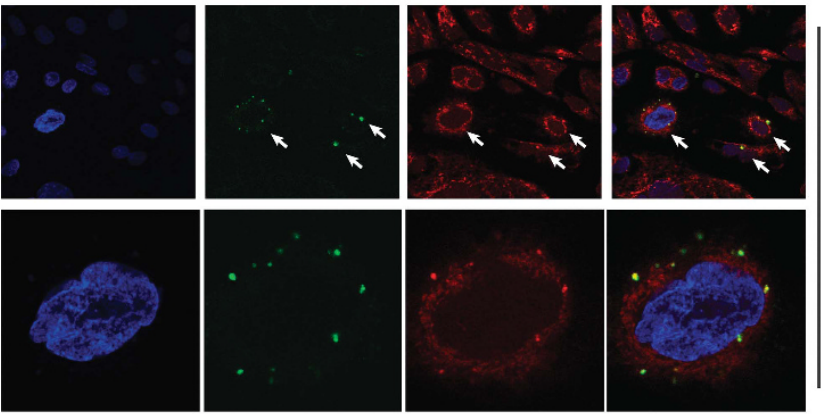

TNF $\alpha / C H X$

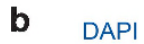

Casp8(FLICA)

NLRP3

Merge
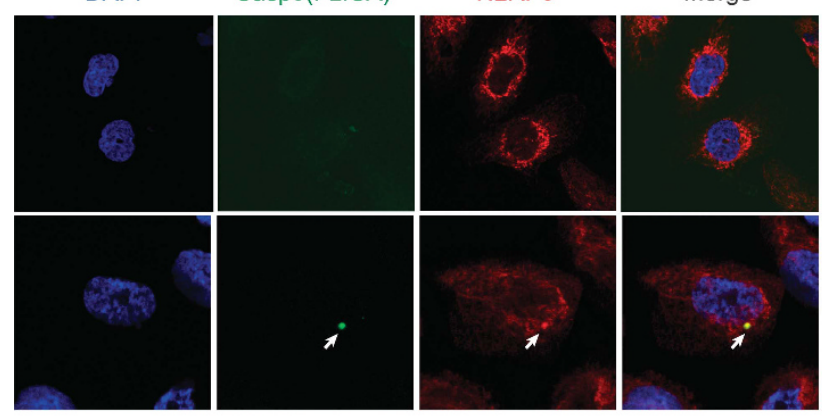

Untreated

c DAPI

Casp8(FLICA)
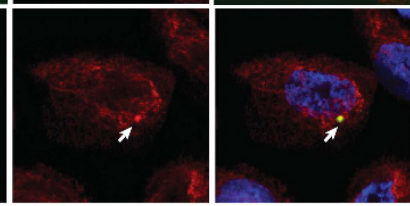

$\mathrm{TNF} \alpha / \mathrm{CHX}$

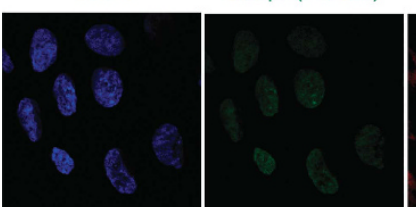

ASC

Merge
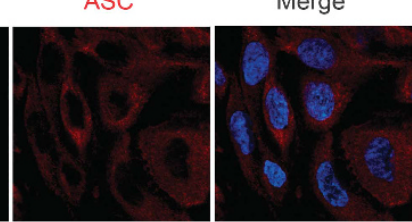

Untreated
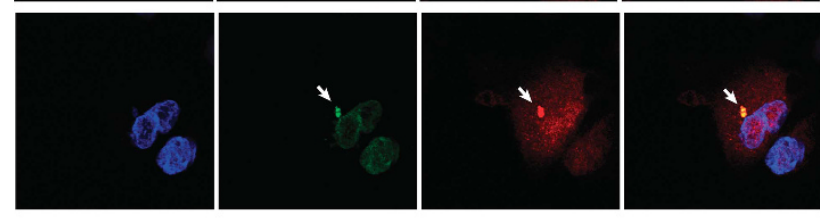

$\mathrm{TNF} \alpha / \mathrm{CHX}$

d DAPI

Casp8(FLICA)

ASC

NLRP3
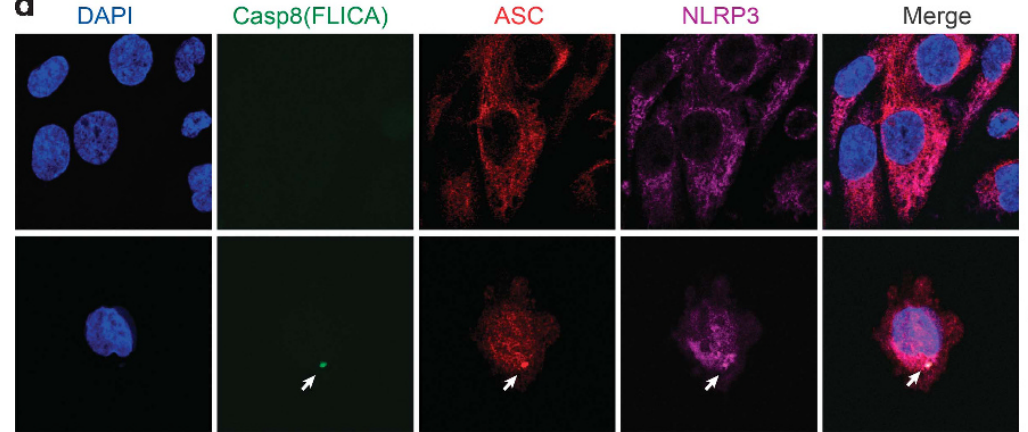

Untreated

$\mathrm{TNF} \alpha / \mathrm{CHX}$

Figure 5 Co-localization of activated caspase-8, NLRP3 and ASC in HPTC. (a) Immunofluorescence confocal microscopy. Activated caspase-8 (FLICA, green) and mitochondria (Mitotracker Red) in untreated and TNF $\alpha(10 \mathrm{ng} / \mathrm{ml}) / \mathrm{CHX}(25 \mu \mathrm{g} / \mathrm{ml})$-treated HPTC $(24 \mathrm{~h})$. Upper panels are $\times 40$ lens $\times 2$ zoom, lower panels $\times 60$ lens, $\times 4$ zoom. Arrows denote cells with active caspase-8 co-localizing to mitochondria. Caspase-8 co-localization with (b) NLRP3 (red) and (c) ASC (red) in HPTC untreated and treated with $\mathrm{TNF} \alpha / \mathrm{CHX}$ at $24 \mathrm{~h}$. Upper panels $\times 40$ lens $\times 2$ zoom, lower panels $\times 60$ lens, $\times 3$ zoom. (d) Co-localization of NLRP3 (magenta), ASC (red) and caspase-8 (green, FLICA) in untreated and treated HPTC $(24 \mathrm{~h})(\times 60$ lens, $\times 3$ zoom). All cells were background stained with DAPI (blue) 
confirming ASC oligomerization during THFa/CHX-induced apoptosis in HPTC (Figures $6 a$ and b). Using a similar approach in mouse TEC, active caspase-8 and ASC monomers emerged in the mitochondrial fraction following $\mathrm{TNF} / \mathrm{CHX}$ stimulation (Figure 6c). In contrast, caspase-8 activation and ASC expression at the mitochondria

a

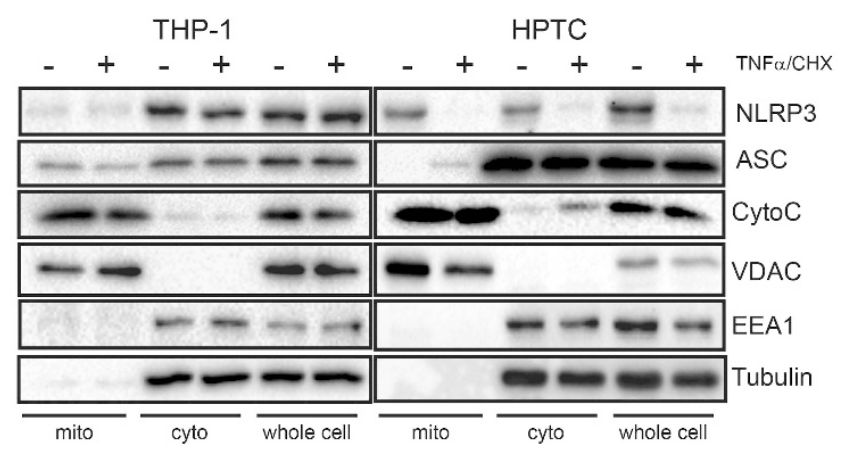

b

HPTC

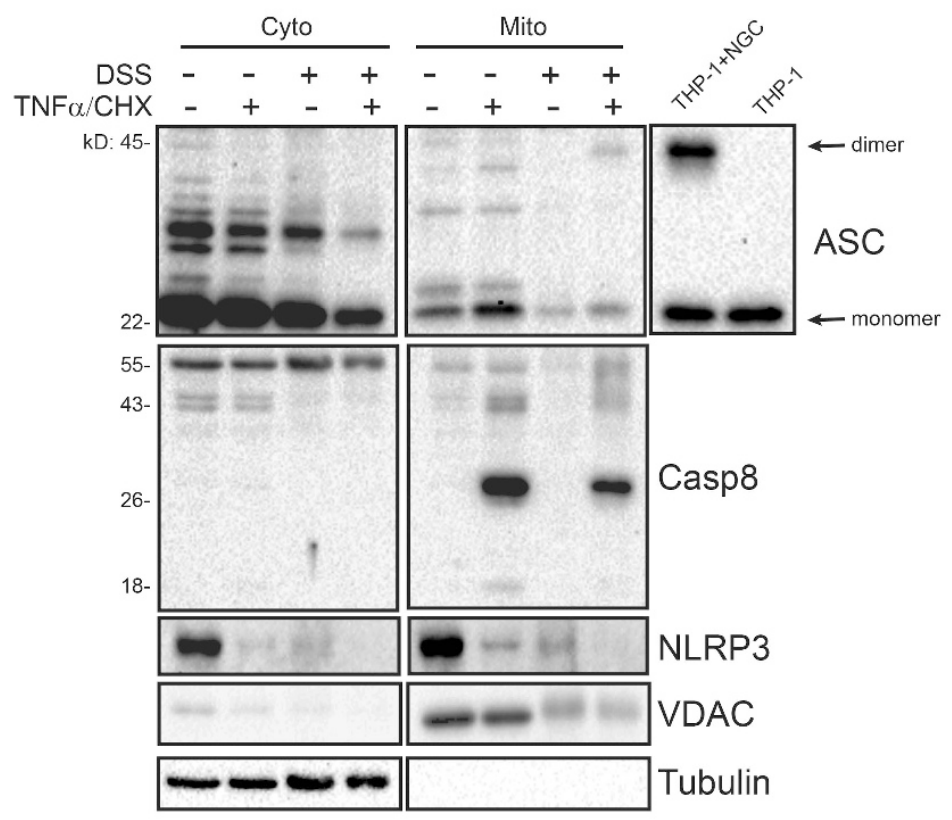

c

mTEC

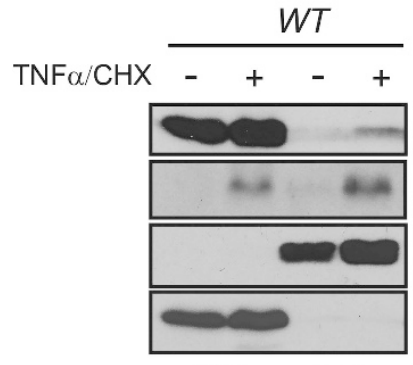

Cyto Mito
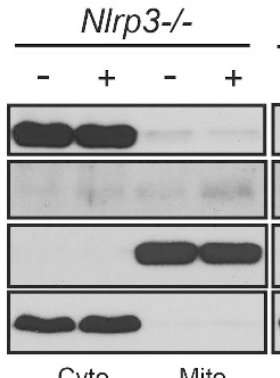
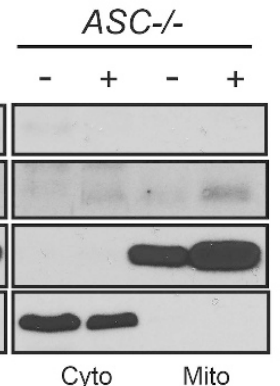

ASC

Casp8(p18)

COXIV

Tubulin

Figure 6 Cellular localization of NLRP3, ASC and Caspase-8. (a) Mitochondrial and cytoplasmic fractionation in HPTC and THP-1 macrophages at baseline and following TNF $\alpha(10 \mathrm{ng} / \mathrm{ml}) / \mathrm{CHX}(25 \mu \mathrm{g} / \mathrm{ml})$ treatment at $24 \mathrm{~h}$. Immunoblotting for the indicated proteins. Cytochrome $c / V D A C$ and tubulin/EEA1 are mitochondrial and cytoplasmic protein controls, respectively. (b) Cytosolic and mitochondrial fractionation of HPTC treated with TNF $\alpha / \mathrm{CHX}$ at $24 \mathrm{~h}$. Uncrosslinked and disuccinimidyl suberate (DSS)-crosslinked protein fractions were analyzed by immunoblotting as indicated. Arrows denote ASC monomer and dimer forms. Tubulin and the voltage-dependent anion channel, VDAC, are cytosolic and mitochondrial control markers, respectively. (c) Subcellular fractionations (cytosolic and mitochondrial) in wild-type (WT) NIrp3-/- and ASC - / - TECs after $24 \mathrm{~h}$ treatment with TNF $\alpha(10 \mathrm{ng} / \mathrm{ml}) / \mathrm{CHX}(5 \mu \mathrm{g} / \mathrm{ml})$. Cytosolic fractions were chloroform/methanol precipitated before analysis for the indicated proteins (immunoblotting). Tubulin and COX IV are cytosolic and mitochondrial control markers, respectively 
was reduced or absent in NIrp3-/- and ASC-/- TECs. Together, these data support the immunofluorescence data and the conclusion that NLRP3, ASC and caspase-8 form a non-canonical protein complex at the mitochondria during receptor-mediated apoptosis in kidney epithelium.

NLRP3, ASC and caspase-8 complexes are activated by multiple mechanisms in epithelial cells. To assess the relationship between death receptor signaling and NLRP3dependent apoptosis, experiments were performed examining RIP1, FADD and TRADD. As expected, the RIP1 inhibitor necrostatin-1 effectively blocked caspase-8 activation induced by TNFa/birinapant (Supplementary Figure S13a) but had no effect on caspase-8 activation or NLRP3/ASC/caspase-8 speck formation induced by $\mathrm{TNF} / \mathrm{CHX}$ (Supplementary Figures S13b and c). Next, siRNA was used to knock down TRADD and FADD in HPTC. Not surprisingly, in response to TNFa/CHX, both FADD and TRADD were required for optimal caspase-8 activation compared with control cells (Figure 7a). Using confocal microscopy, both FADD and TRADD colocalized to ASC specks, caspase-8 (FLICA) and NLRP3 in HPTC stimulated with $\mathrm{TNFa} / \mathrm{CHX}$ (Figures $7 \mathrm{~b}-\mathrm{d}$ ), supporting the involvement of TNFR signaling, FADD and TRADD in the activation of caspase- 8 and the formation of NLRP3/ASC/ caspase-8 complexes. The siRNA procedure, however, was not sufficient enough to detect a change in NLRP3/ASC/ caspase-8 speck formation microscopically.

The NLRP3-dependent activation of caspase-8, however, may not be specific to any single apoptotic mechanism, and the co-localization of FADD/TRADD to NLRP3/ASC/caspase8-positive specks may simply be a reflection of the involved death receptor pathway. In TECs treated with $\mathrm{CHX}$ alone, which can induce apoptosis through its effect on protein synthesis, ${ }^{30,31}$ a small increase in cell death, apoptosis and caspase- 8 activation could be observed that was dependent on Nirp3 (Supplementary Figures S14a-c). Furthermore, induction of intrinsic apoptosis using etoposide also triggered caspase- 8 and -9 activation in TECs that was dependent on NIrp3 (Supplementary Figures S14d and e), suggesting that NLRP3 may represent a more generalized platform for caspase-8 activation at the mitochondria in epithelial cells.

Canonical inflammasome activation downstream of multiple pathogen and danger-associated molecular patterns is believed to converge on a single common pathway such as potassium $(\mathrm{K}+)$ efflux. ${ }^{32}$ To examine the potential role of $\mathrm{K}+$ efflux in the regulation of apoptosis and NLRP3/ASC/ caspase-8 complex formation, HPTC were stimulated with $\mathrm{TNF} / \mathrm{CHX}$ in the presence of extracellular $\mathrm{KCl}$ and monitored for caspase-3 and -7 activity by live cell fluorescence microscopy. TNFa/CHX induced progressive apoptosis in HPTC that became detectable between 6 and $12 \mathrm{~h}$ and was effectively inhibited by extracellular $\mathrm{KCl}$ (Figure $8 \mathrm{a}$ ). $\mathrm{KCl}$ also blocked TNFa/CHX-induced caspase-8 activation (Figure 8b). Consistent with these data, NLRP3/ASC/caspase-8 specks that are detectable as early as $12 \mathrm{~h}$ by fluorescence microscopy in TNFa/CHX-treated HPTC were absent and substantially reduced at 12 and $24 \mathrm{~h}$, respectively, in the presence of extracellular $\mathrm{KCl}$ (Figure $8 \mathrm{c}$ ). Thus these data show that NLRP3/ASC/caspase-8 complexes form in parallel with apoptosis in a process that is dependent on $\mathrm{K}+$ efflux.
NIrp3 regulates epithelial ASC speck formation in intestinal enteroids and during kidney injury in vivo. To confirm that ASC speck formation during apoptosis was not restricted to kidney epithelial cells, studies were performed in primary intestinal enteroids derived from the ceca of wild-type and NIrp3-/- mice. Enteroids are comprised of an epithelial cell monolayer devoid of macrophages and other leukocytes. ${ }^{33}$ Enteroids are also type II cells that cleave Bid in response to TNFa/CHX and undergo apoptosis, which disrupts the enteroid structure (Figures 9a and b). NIrp3-/- enteroids displayed a significant reduction in caspase-8 activation and Bid cleavage following $\mathrm{TNF} / \mathrm{CHX}$ treatment compared with wild-type controls (Figures $9 \mathrm{~b}$ and $\mathrm{c}$ ). Similar to kidney epithelial cells, NIrp3- and ASC-positive specks could be readily seen in TNFa/CHX-treated enteroids as cells became apoptotic and sloughed from the monolayer (Figure 9d). ASC speck formation was significantly reduced in NIrp3-/enteroids, confirming that NIrp3 has a role in regulating this process during epithelial apoptosis (Figure 9d). These data support the concept that the regulation of caspase-8 by NIrp3 during apoptosis may also occur in other epithelial tissues.

Our previous studies have demonstrated reduced epithelial cell apoptosis during tubular injury induced by UUO in NIrp3-/- mice. ${ }^{20}$ To determine whether epithelial cell injury in this model was associated with tubular ASC speck formation, wild-type, NIrp3-/- and $A S C-/-$ mice underwent UUO and the kidneys were analyzed by immunofluorescence microscopy. NIrp3-/- kidneys displayed significantly less tubular staining for cleaved caspase-3 compared with wild-type kidneys following UUO injury at 14 days confirming a reduction in apoptosis (Figure 10a). In line with the in vitro studies, immunofluorescence revealed significant amounts of ASC-positive specks in E-cadherin-positive tubules in the injured wild-type kidneys that were substantially reduced or absent in NIrp3-/-, $A S C-/-$ or sham-treated mice (Figure 10b). Thus these data support the conclusion that Nlrp3 regulates epithelial cell apoptosis and tubular epithelial ASC speck formation during kidney injury in vivo.

\section{Discussion}

In this study, we elucidate the non-canonical function of NLRP3 in epithelium and highlight the ongoing crosstalk between the inflammasome and apoptosis machinery in the cell. NLRP3 and ASC form a non-canonical caspase-8activating platform in epithelial cells that impacts apoptosis, a central process in the pathogenesis of kidney and gastrointestinal disease. The assembly of an NLRP3-ASC-caspase-8 protein complex described in this study occurred in the absence of caspase-1 or pro-inflammatory cytokine production and thus cannot be accurately described as an inflammasome. We propose that, in the absence of a clear inflammatory effector function, NLRP3 and ASC assembly at mitochondria in epithelial cells represents a non-canonical apoptosome for caspase-8 activation (Figure 10c).

The regulation of caspase- 8 by NLRP3 identifies cell-context-specific functions for Nod-like receptors and inflammasomes in epithelial cells and leukocytes. The differential but related function of NLRP3 in these cell types also highlights the hierarchical organization of host defense 
mechanisms that ensure appropriate responses to varying degrees of injury, essential to maintain tissue homeostasis. In macrophages and dendritic cells, the activation of caspase- 8 occurs downstream of NLRP3, AIM2 and NLRC4 inflammasomes in response to canonical triggers such as dsDNA and Salmonella infection that contributes largely to a

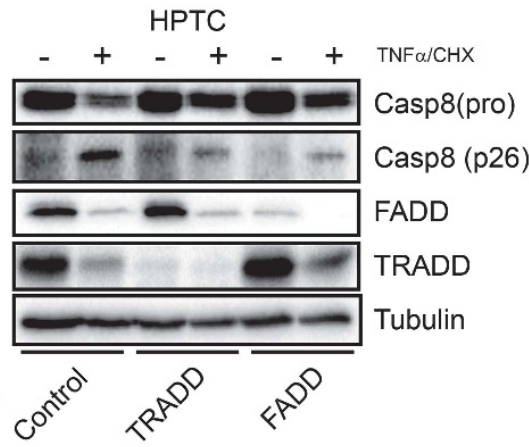

b

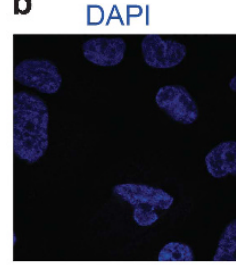

Casp8(FLICA)
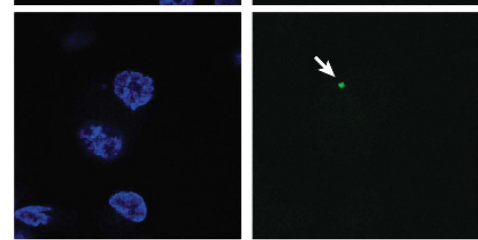

c DAPI

Casp8(FLICA)
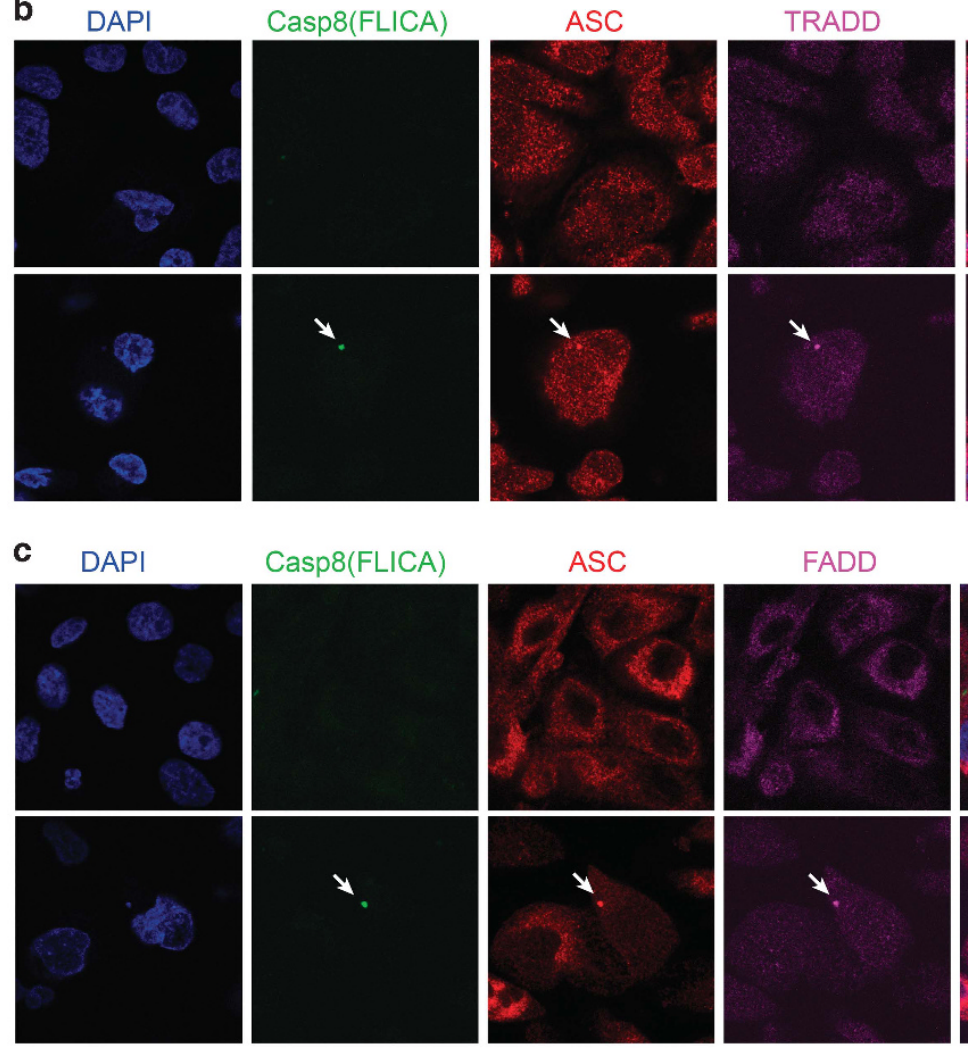

FADD

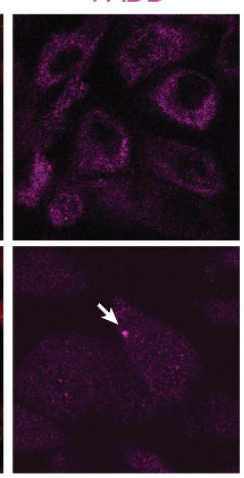

No Treatment

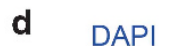

Casp8(FLICA)

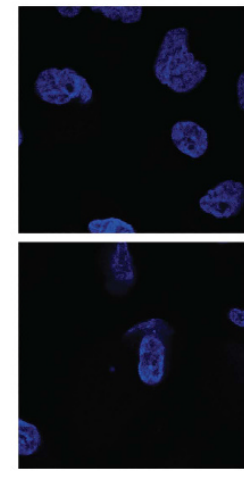

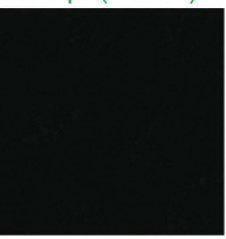
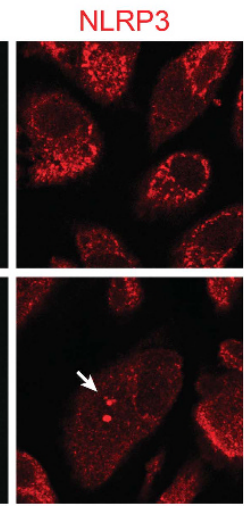

TRADD

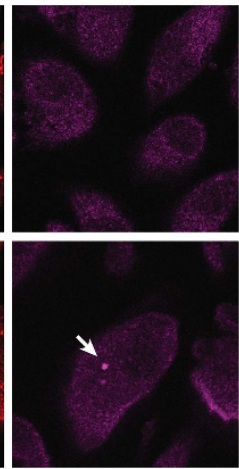

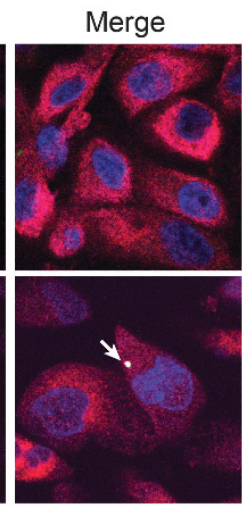

Merge

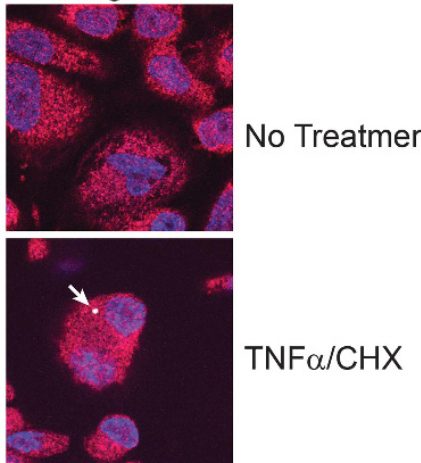

Merge

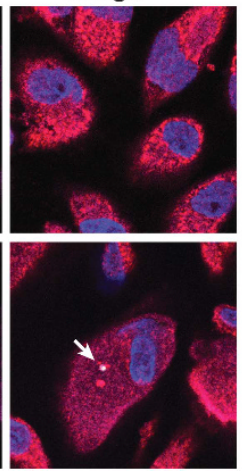

No Treatment

$\mathrm{TNF} \alpha / \mathrm{CHX}$ 
cytokine maturation. 4,12,13,16,17 Although inflammasomedependent caspase-8 activation contributes to apoptosis in macrophages, ${ }^{4,12}$ our data, in contrast, demonstrates a direct role for NLRP3 in receptor-mediated cell death independent of the inflammasome in epithelial cells. We do not detect NLRP3dependent cytokine secretion or a canonical caspase-1activating inflammasome in proximal tubular epithelial cells. The variables that determine inflammasome formation in kidney epithelial cells remain to be determined but not likely related to caspase-1 expression or cellular priming. The differential regulation of apoptosis and inflammasome activation between cell types, however, may be related to the cellular localization of NLRP3, which is largely cytoplasmic in macrophages and mitochondrial in tubular epithelial cells.

The effect of NLRP3 and ASC in the regulation of caspase-8 in tubular epithelial cells affected primarily the type II cell death phenotype where death receptor-mediated apoptosis requires mitochondrial amplification to fully execute apoptosis. Cardiolipin, which also interacts with NLRP3, ${ }^{29}$ acts as an anchor and activating platform for caspase- 8 in the mitochondria in type II apoptotic cells. ${ }^{9}$ Several proteins have also been suggested to interact with caspase-8 in the mitochondria, including mitochondrial-antiviral signaling protein which is known to interact with NLRP3. ${ }^{34-38}$ Whether any of these proteins or cardiolipin have a role in the assembly of an NLRP3-dependent-activating platform for caspase-8 remains to be determined.

The mechanism of NLRP3/ASC/caspase-8 complex formation does not appear to be specific to any single apoptosis pathway and may represent a general platform induced at the mitochondria regardless of the stimulus, similar to the mechanism of canonical NLRP3 inflammasome activation in macrophages. First, NIrp3 regulated caspase-8 activation downstream of multiple pathways involving TNFR, CD95 and non-death receptor apoptosis triggered by etoposide. Second, the impact of $\mathrm{K}+$ on epithelial cell apoptosis and the formation of the non-canonical NLRP3/ASC/caspase-8 platform implies that multiple mitochondrial cell death pathways may converge on a single mechanism to that involving NLRP3. Clearly more work is required to further dissect the essential players that regulate the NLRP3-dependent cell death pathway in epithelial cells.

In summary, our data provides insight into the role of NLRP3 in epithelial cells in response to injury. In addition to regulating the inflammasome and cytokine secretion in macrophages, NLRP3 regulates caspase-8 and apoptosis in the epithelium through the formation of a non-canonical protein complex at the mitochondria. This work emphasizes NLRP3 as a multifaceted protein that impacts, in a cell-context-specific manner, inflammation and death pathways that are central to tissue homeostasis, host response to infection/injury and the pathogenesis of disease.
Materials and Methods

Mice. NIrp3 $-/-{ }^{39}$ ASC $-/-{ }^{40}$ and caspase $1 / 11-/-{ }^{41}$ were on a C57BI/6 background and housed under standard conditions. Mice were used between 8 and 12 weeks of age. NIrp3 - / - and wild-type C57BI/6 control mice used in this study were derived from Nirp3-/+ mice. Nirp3 heterozygotes were derived from NIrp3 - / - mice crossed with C57BI/6 mice (Charles River, Wilmington, MA, USA). Unilateral ureteric obstruction model was performed as previously described. ${ }^{20}$

Primary cell culture. TECs were isolated from the kidneys harvested from mice between the ages of 8-12 weeks. Under sterile conditions, the capsules surrounding the kidneys were detached, and the renal cortex was removed with a sterile scalpel. Renal cortex tissues were placed in $1.5 \mathrm{mg} / \mathrm{ml}$ collagenase/HBSS (Sigma-Aldrich, St. Louis, MO, USA) solution and incubated at $37^{\circ} \mathrm{C}$ with $5 \% \mathrm{CO}_{2}$ for $60 \mathrm{~min}$. Tissue was homogenized using sterile microscope slides and then passed through 70- $\mu \mathrm{m}$ nylon filters. The cell suspension was spun down for $5 \mathrm{~min}$ at $230 \times g$ to remove excess collagenase and washed twice more in $1 \times$ HBSS. The cell pellet was resuspended in K1 media (10\% fetal bovine serum (FBS), $1 \%$ penicillin-streptomycin, $1 \%$ hormone mix (ITSS media supplement, $350 \mathrm{nM}$ prostagladin $\mathrm{E}_{1}, 5 \mathrm{nM} 3,3^{\prime}, 5$-triiodo-L-thyronine sodium salt, $5 \mu \mathrm{M}$ hydrocortisone, $10 \mathrm{mM}$ HEPES pH 7.4), $25 \mathrm{ng} / \mathrm{ml}$ mouse EGF, $25 \mathrm{mM}$ HEPES pH 7.4 in DMEM/ $\mathrm{F} 12)$ and plated onto tissue culture plates for $1-2 \mathrm{~h}$ at $37^{\circ} \mathrm{C}$ to remove contaminating fibroblasts and endothelial cells. The cell suspension was then replated onto collagen-IV-coated plates and allowed to grow overnight at $37^{\circ} \mathrm{C}$. Cells were washed and media changed the next day. Cells were maintained in $\mathrm{K} 1$ media and allowed to grow to confluence before passage onto experimental plates. All in vitro experiments were completed within two cell passages. Cells were confirmed to be epithelial cells periodically by ZO-1 or E-cadherin immunofluorescence staining for tight junction formation.

HPTCs were isolated from non-diseased nephrectomy samples from patients with renal cell carcinoma. Nephrectomy samples were placed in clean HBSS on ice for transport before isolation. Subsequent steps were performed in a biosafety cabinet under sterile conditions. The capsule and medulla were dissected away from the cortex. Minced renal cortex tissues were then placed in a $1.5 \mathrm{mg} / \mathrm{ml}$ collagenase/ HBSS (Sigma) solution and incubated at $37^{\circ} \mathrm{C}$ for $60 \mathrm{~min}$. Tissue was homogenized using two sterile microscope slides and then passed through a $70-\mu$ m nylon filter. The filtered cell suspension was then spun down for $10 \mathrm{~min}$ at $230 \times \mathrm{g}$ to remove excess collagenase and washed two times in $1 \times$ HBSS. The cell pellet was resuspended in HPTC media (10\% FBS, 1\% penicillin-streptomycin, 1\% hormone mix, $25 \mathrm{ng} / \mathrm{ml}$ human EGF, $25 \mathrm{mM}$ HEPES pH 7.4 in DMEM/F12) and plated onto uncoated tissue culture plates for $1 \mathrm{~h}$ at $37^{\circ} \mathrm{C}$. After $1 \mathrm{~h}$, the cell suspension was re-plated onto collagen-IV-coated plates and allowed to grow overnight at $37^{\circ} \mathrm{C}$. Cells were washed and media changed the following day.

Bone marrow macrophages were isolated from the femurs and tibia of mice between the ages of 8-12 weeks. The bone marrow was collected on ice in HBSS. Cells were washed twice with HBSS and spun down at $230 \times \mathrm{g}$ for $5 \mathrm{~min}$. Macrophages were plated onto tissue culture plates and maintained for $48 \mathrm{~h}$ in L929cell media followed by a fresh media change. Macrophages were utilized 7 days after isolation.

Primary peritoneal macrophages were isolated from mice between the ages of 8-12 weeks. Mice were injected with $4 \%$ thioglycollate solution (BD Biosciences, San Jose, CA, USA) $72 \mathrm{~h}$ before peritoneal lavage. The peritoneal cavity was lavaged under sterile conditions with $10 \mathrm{ml}$ RPMI media and kept on ice. The cells were spun down at $230 \times g$ for 5 min before the addition of red cell lysis buffer for 5 min on ice. Cells were washed twice with RPMI media supplemented with $10 \%$ FBS, $1 \%$ penicillin-streptomycin and $50 \mathrm{nM}$ 2-mercaptoethanol and plated onto tissue culture plates.

Mouse cecal enteroid cultures were established using protocols based on methods previously established by Sato et $a l^{33}$ Stem cell-containing intestinal crypts were recovered from the ceca of both wild-type C57BL/6 and N/rp3 - / - mice. Briefly, the cecum was removed from male 8-week-old mice, cut open longitudinally and washed

Figure 7 Involvement of FADD and TRADD in caspase-8 activation and NLRP3/ASC speck formation. (a) Immunoblotting for pro-caspase-8, caspase-8 p26 cleavage product (N-terminal DED-domain) in HPTC transfected with control (scramble) siRNA or siRNAs targeting FADD and TRADD. HPTC were treated with TNF $\alpha$ (10 ng/ml)/CHX $(25 \mu \mathrm{g} / \mathrm{ml})$ and analyzed at $24 \mathrm{~h}$. FADD and TRADD immunoblotting demonstrates efficacy of RNA interference and protein knock down. (b) Confocal immunofluorescence microscopy probing for activated caspase-8 (green, FLICA), ASC (red), TRADD (magenta) or (c) FADD (magenta) in HPTC treated with TNF $\alpha / \mathrm{CHX}$ at $24 \mathrm{~h}$. (d) Confocal immunofluorescence microscopy probing for activated caspase-8 (green, FLICA), NLRP3 (red) and TRADD (magenta) in HPTC treated with TNF $\alpha /$ CHX at $24 \mathrm{~h}(\times 60$ lens, $\times 3$ zoom). Arrows denote co-localizing proteins. Images are representative of two independent experiments 
a

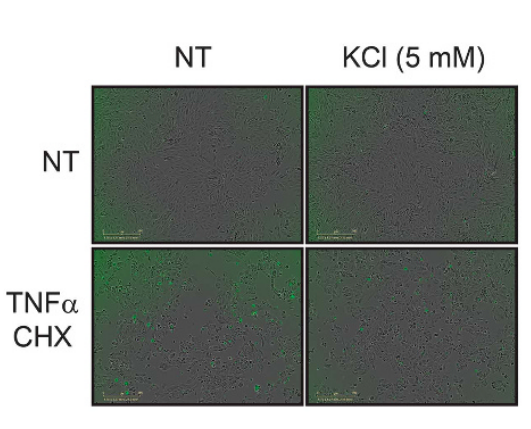

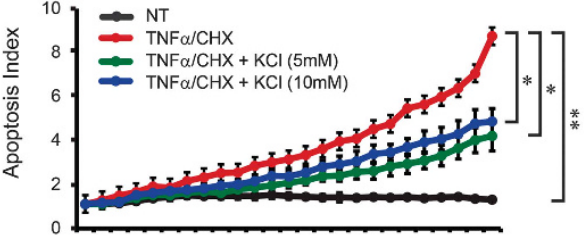

$\begin{array}{llllllllllll}2 & 4 & 6 & 8 & 10 & 12 & 14 & 16 & 18 & 20 & 22 & 24\end{array}$ Time (hrs)

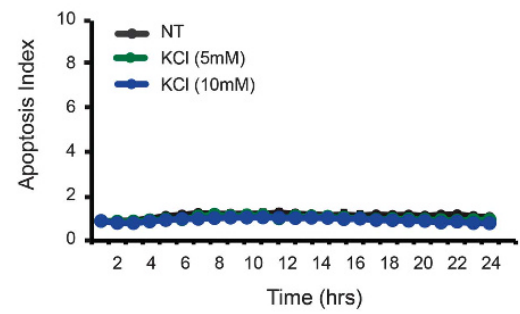

b

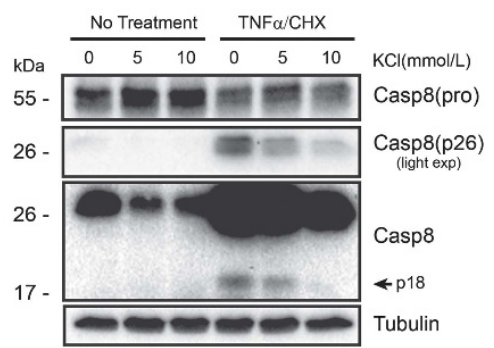

C

DAPI
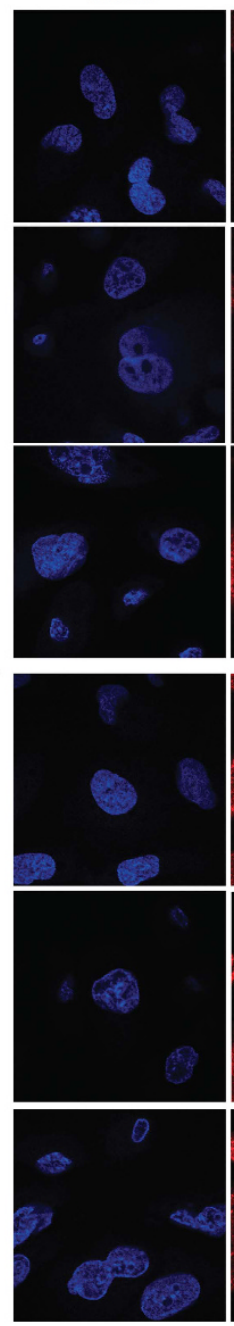

NLRP3
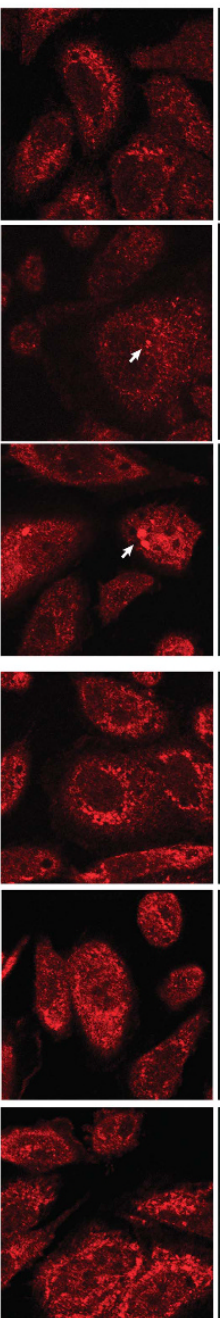

Casp8(FLICA)
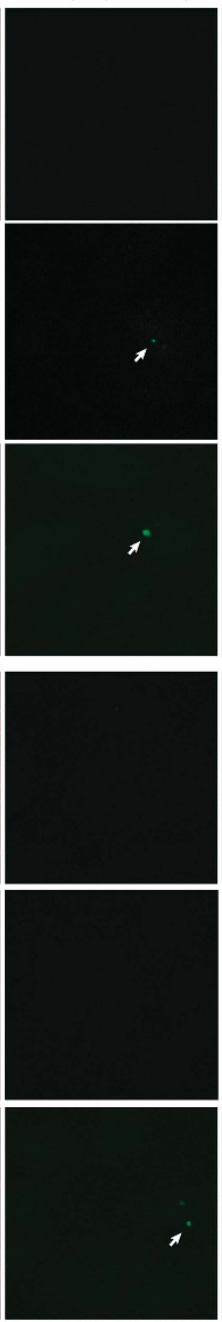

ASC
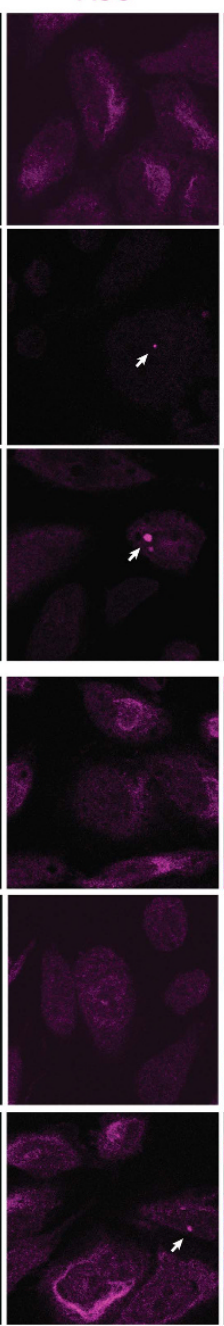

Merge

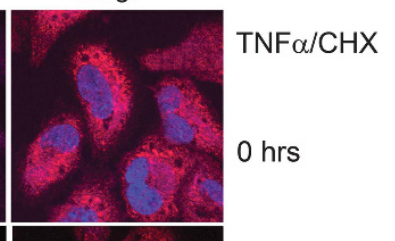

$12 \mathrm{hrs}$

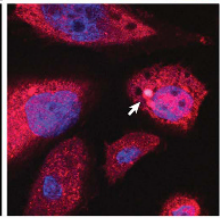

$24 \mathrm{hrs}$

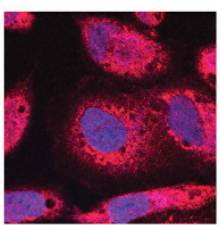

$0 \mathrm{hrs}$

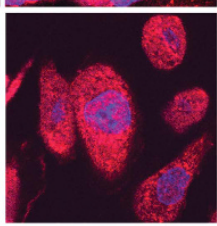

12 hrs

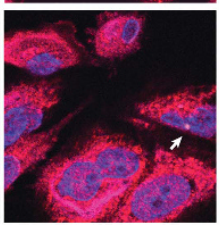

$24 \mathrm{hrs}$

Figure 8 Potassium efflux and epithelial cell apoptosis, caspase-8 activation and NLRP3/ASC/caspase-8 complex formation. (a) Live cell fluorescence imaging and quantification of caspase-3 and -7 activity over a 24-h time course in HPTC untreated (NT) or TNF $\alpha(10 \mathrm{ng} / \mathrm{ml} / \mathrm{CHX}(25 \mu \mathrm{g} / \mathrm{ml})$ stimulated with or without the addition of 5 or $10 \mathrm{mmol} / \mathrm{l}$ of extracellular $\mathrm{KCl}$ to the cell culture medium (mean \pm S.E.M., $n=3$ for each time point. TNF $\alpha / \mathrm{CHX}$ versus no treatment, ${ }^{* *} P<0.01 ; \mathrm{TNF} \alpha / \mathrm{CHX}$ versus $\mathrm{TNF} \alpha / \mathrm{CHX}+\mathrm{KCl},{ }^{*} P<0.05$ ). Left images of HPTC at $24 \mathrm{~h}$ treated with TNF $\alpha / \mathrm{CHX}$ and extracellular KCL as indicated. Representative of experiment performed three times. (b) Immunoblotting for pro-caspase-8 and caspase-8 (p26 and p18) in TNF $\alpha / C H X$-treated HTPC cultured in 0,5 or $10 \mathrm{mmol} / \mathrm{l}$ of extracellular KCl at $24 \mathrm{~h}$. (c) Confocal immunofluorescence microscopy probing for activated caspase-8 (green, FLICA), NLRP3 (red) and ASC (magenta) in HPTC treated with TNF $\alpha / C H X$ at 0,12 and $24 \mathrm{~h}$ with or without the addition of $5 \mathrm{mmo} / /$ of extracellular potassium to the cell culture medium ( $\times 60$ lens, $\times 3$ zoom). Arrows denote NLRP3/ASC/caspase-8-positive specks. Representative images of two independent experiments 
a

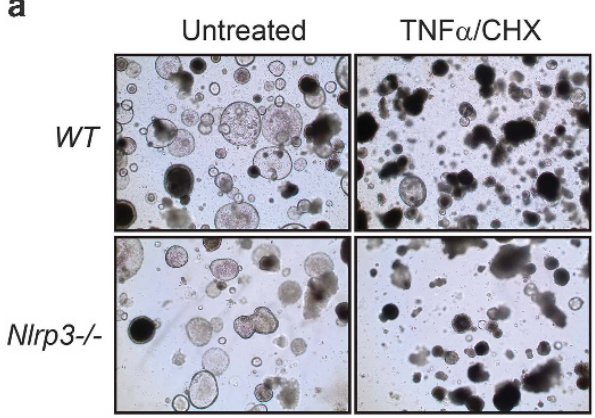

Cecum Enteroids

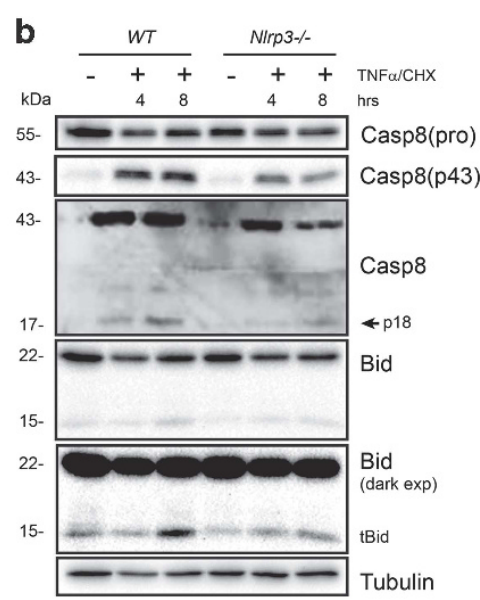

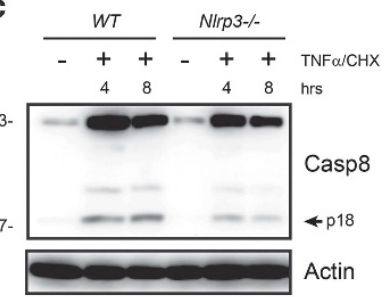

d

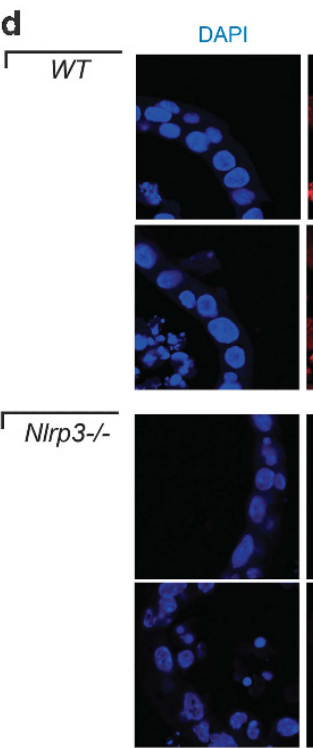

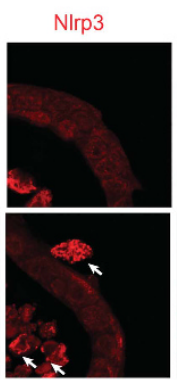
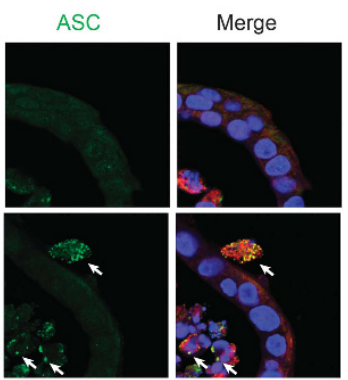

Untreated
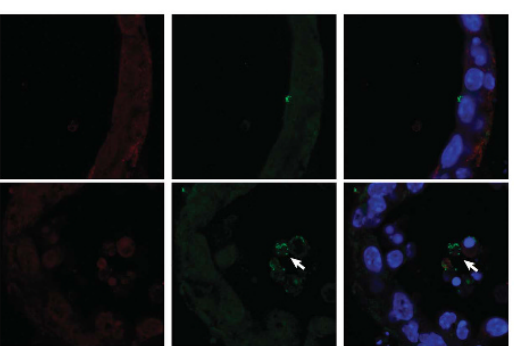

$\mathrm{TNF} \alpha / \mathrm{CHX}$

Figure 9 NIrp3-dependent caspase-8 activation and ASC speck formation in cecal-derived enteroids. (a) Brightfield microscopy of cecal enteroids suspended in matrigel following 7 days of growth at $\times 4$ magnification. Healthy wild-type (WT) and N/rp3 - / - enteroids (left panels) are compared against enteroids following $6 \mathrm{~h}$ of exposure to TNF $\alpha$ $(10 \mathrm{ng} / \mathrm{ml}) / \mathrm{CHX}(5 \mu \mathrm{g} / \mathrm{ml})$ (right panels). (b) Immunoblotting for caspase-8 (pro, p43 and p18) and Bid in WT and Nlrp3-/- cecal enteroids treated with TNF $\alpha / \mathrm{CHX}$. (c) Immunoblotting for caspase-8 in a second independent set of WT and NIrp3 - / - cecal enteroids at 4 and $8 \mathrm{~h}$ following exposure to TNF $\alpha / \mathrm{CHX}$. (d) Immunofluorescence confocal microscopy of untreated and TNF $\alpha / C H X$ treated WT and NIrp3- / - cecal enteroids. NLRP3 (red), ASC (green) and DAPI (blue) at $\times 100$ magnification. Co-localized NLRP3 and ASC specks are visible in WT cells at various stages of apoptosis and sloughing but not in NIrp3- / - cells and only rarely in WT healthy cells still maintaining the enteroid's epithelial monolayer

repeatedly in sterile PBS containing gentamicin and penicillin/streptomycin. The washed cecal tissue was incubated for $30 \mathrm{~min}$ at $4^{\circ} \mathrm{C}$ in cell recovery solution (Corning, NY, USA) to detach the cecal epithelium from the surrounding muscle and connective tissue. The epithelium was gently scraped off and then vortexed briefly to detach individual crypts. Crypts were washed twice in Advanced DMEM/F12 containing penicillin/streptomycin, HEPES buffer and Glutamax (Gibco, Thermo-Fisher Scientific, Waltham, MA, USA, hereby referred to as MEM+++), suspended in matrigel (Corning), and plated as 30-40 $\mu \mathrm{l}$ drops in 24-well plates (Corning). Cecal enteroids were grown routinely in growth media containing MEM++ +, R-spondin, Noggin and Wnt3A conditioned media, ${ }^{42}$ N2 supplement (Invitrogen, Grand Island, NY, USA), B27 supplement (Invitrogen), mEGF (Invitrogen), A83-01 (Tocris, Bristol, UK), SB202190 (Sigma-Aldrich), N-acetylcysteine (Sigma-Aldrich) and nicotinamide (Sigma-Aldrich), as described by Sato et al. ${ }^{33}$ The media was changed every 2-3 days, and the resultant enteroid cultures were split one to four, every 7 days.

This growth medium allowed for the rapid growth and propagation of mouse cecal enteroids, however, the addition of Wnt3A, A83-01, SB202190 and nicotinamide is known to inhibit the differentiation and maturation of certain cell types, including mature enterocytes and goblet cells. ${ }^{33}$ To account for this in experimental cultures, 4 days prior to treatment with TNF $\alpha / C H X$, nicotinamide, A83-01 and SB202190 were omitted from the media, and the Wnt3A conditioned media was reduced by $50 \%$, with the volume being balanced with additional MEM+++. Twenty four hours prior to treatment, the Wnt3A conditioned medium was omitted entirely as well and $100 \mathrm{ng} / \mathrm{ml}$ LPS (Sigma-Aldrich) was supplemented.

The human myelogenous leukemia THP-1 cell line were purchased from the American Type Culture Collection (ATCC, Manassas, VA, USA). THP-1 cells were cultured in RPMl 1640 media (Gibco, Thermo-Fisher Scientific) supplemented with $10 \% \mathrm{v} / \mathrm{v}$ heat-inactivated FBS, $0.05 \mathrm{mM} \beta$-mercaptoethanol and $1 \mathrm{mM}$ sodium pyruvate. Cells were maintained in cell suspension in a $37^{\circ} \mathrm{C}, 5 \% \mathrm{CO}_{2}$, humidified incubator. Cells were differentiated with $100 \mathrm{nM}$ phorbol-12-myristate-13-acetate (Sigma-Aldrich) for $24 \mathrm{~h}$ prior to experiments.

Apoptosis and inflammasome activation. Tubular epithelial cells and macrophages were counted before final plating onto experimental plates. Twelvewell plates were seeded with 25000 cells/well. Six-well plates were seeded with $100000 \mathrm{cells} /$ well. For apoptosis experiments, cells were serum starved overnight 
a
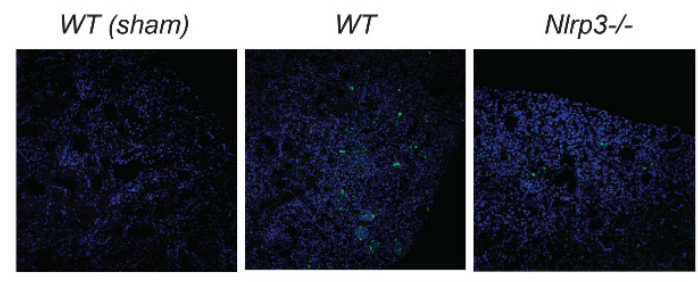

Casp3

UUO d14

b
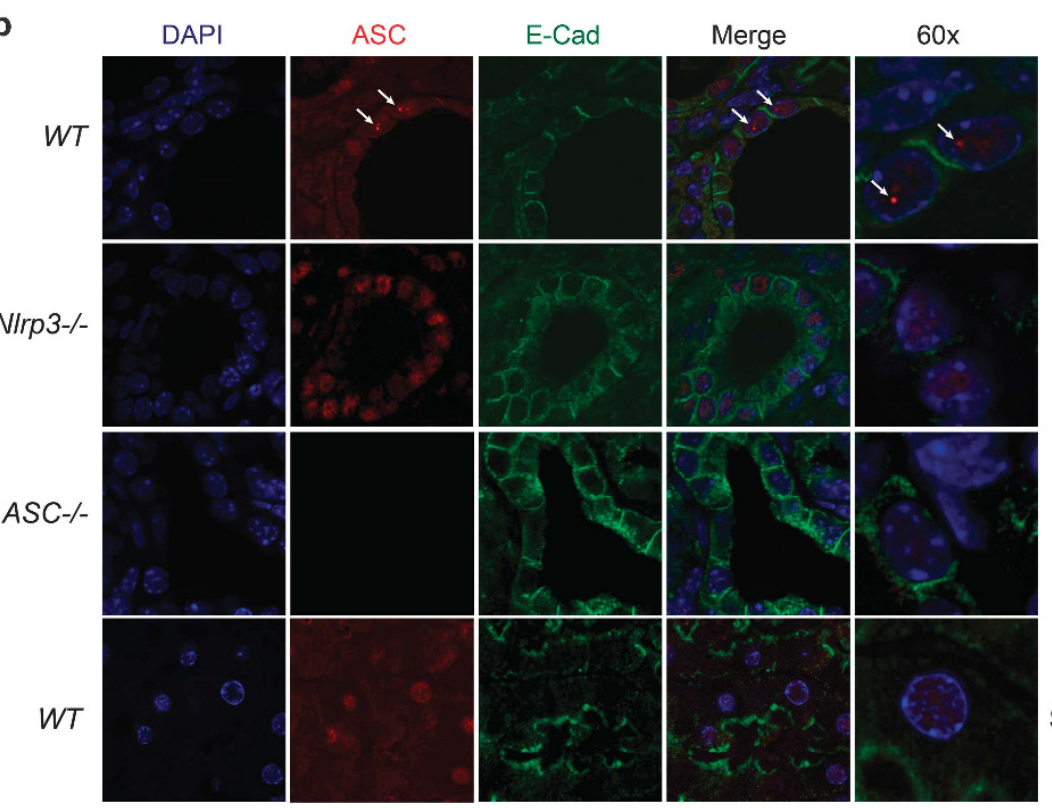

UUO d14
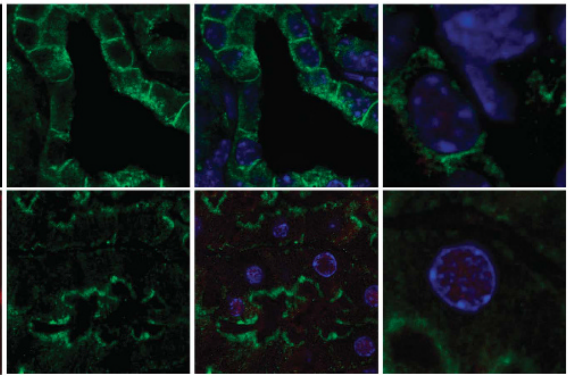

Sham

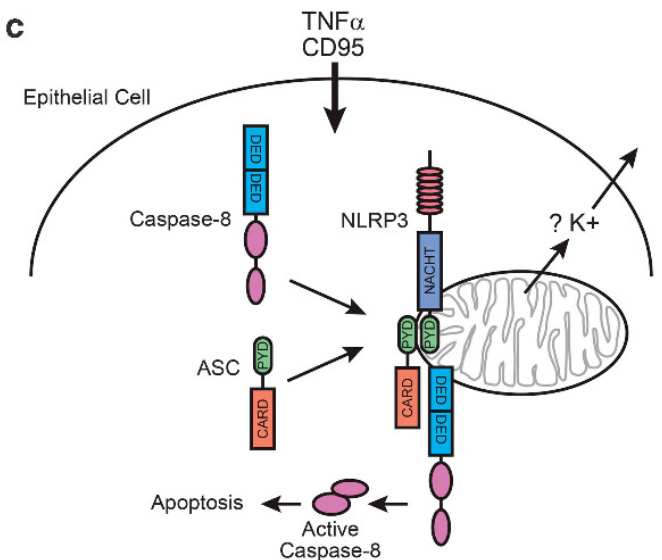

Figure 10 Apoptosis and ASC speck formation in kidney tubular epithelium in vivo. (a) Immunofluorescence probing for activated (cleaved) caspase-3 in the wild-type (WT) or NIrp3 - / - kidney 14 days following UUO (x20 lens). (b) Immunofluorescence for ASC and E-cadherin in the WT, NIrp3 - / - and ASC - / - kidneys at 14 days following UUO. Sham-operated WT mice are shown as controls ( $\times 60$ lens, $\times 4$ zoom, far right panels $\times 10$ zoom). Arrows denote ASC speck formation in E-cadherin-positive tubular epithelial cells. (c) Proposed model of NLRP3-dependent caspase-8 activation during epithelial cell apoptosis

and treated with the following reagents: $\operatorname{TNF} \alpha(10 \mathrm{ng} / \mathrm{ml}), \mathrm{CHX}(5 \mu \mathrm{g} / \mathrm{ml}$ for mouse TEC, enteroids and $25 \mu \mathrm{g} / \mathrm{ml}$ for HPTC, Sigma-Aldrich), birinapant $10 \mu \mathrm{M}$ (Apexbio, Houston, TX, USA), necrostatin-1 (10 $\mu \mathrm{M}$, Sigma-Aldrich), etoposide (100-1000 $\mu \mathrm{M}$, Sigma-Aldrich), and hamster anti-mouse CD95/Fas antibody $40 \mu \mathrm{g} / \mathrm{ml}$ (Jo2 clone, $\mathrm{BD}$ Biosciences), were added at the initiation of the experiment and allowed to incubate for the indicated time points at $37^{\circ} \mathrm{C}$. For inflammasome activation experiments, epithelial cells and macrophages were primed with $100 \mathrm{ng} / \mathrm{m}$ ultrapure LPS as above before incubation for 6 or $24 \mathrm{~h}$ with $250 \mu \mathrm{g} / \mathrm{ml} \mathrm{MSU}$, $5 \mathrm{mM}$ ATP or $20 \mu \mathrm{M}$ nigericin. Supernatants and cell protein lysates were harvested for analysis.
IL-1 $\beta$ and IL-18 ELISAs. TECs were primed overnight with $100 \mathrm{ng} / \mathrm{ml}$ ultrapure LPS before incubation for $24 \mathrm{~h}$ with $\operatorname{TNF} \alpha(10 \mathrm{ng} / \mathrm{ml})+\mathrm{CHX}(5 \mu \mathrm{g} / \mathrm{ml})$, MSU $25 \mu \mathrm{g} / \mathrm{ml}$ or ATP $(5 \mathrm{mM})$. Bone marrow macrophages were incubated with $5 \mathrm{mM}$ ATP for $6 \mathrm{~h}$ as a positive control. IL-1 $\beta$ and IL-18 cytokine secretion was detected in cell supernatants using the ELISA kits from BD Biosciences and eBiosciences (San Diego, CA, USA), respectively, as per the manufacturers' protocol.

Immunoblotting. Protein samples were separated on SDS-PAGE gels under reducing conditions. Proteins were transferred onto nitrocellulose membranes, which were blocked for $1 \mathrm{~h}$ with the appropriate blocking solution before incubating 
overnight at $4{ }^{\circ} \mathrm{C}$ with the primary antibody. Blots were washed with an appropriate buffer and then incubated at room temperature with the secondary antibody in blocking buffer for $1 \mathrm{~h}$ before additional washes. Proteins were visualized using $E C L$ western blotting detection reagents (GE Healthcare, Pittsburgh, PA, USA) and exposed to film or digitally captured using a Chemidoc MP device (Bio-Rad, Hercules, CA, USA). Bands were quantified using the ImageJ (NIH, Bethesda, MD, USA) or Image Lab (Bio-Rad) software and normalized as indicated. Antibodies used are as follows: mouse anti-human NLRP3 (Cryo-2 clone, Adipogen), rabbit anti-human ASC (Adipogen, San Diego, CA, USA), rabbit anti-human PARP1 and cleaved PARP1 (Cell Signaling, Danvers, MA, USA nos. 9542 and 9544), rabbit antihuman caspase-3 (Cell Signaling no. 9662), rabbit anti-mouse caspase-8 (Cell Signaling nos. 8592, 9429 and 4927), rabbit anti-mouse Bid (Abcam, Cambridge, UK no. 10640), rat anti-mouse Bid (clone 8C3, generous gift from Dr. Thomas Kaufmann, University of Bern, Bern, Switzerland), mouse anti-human caspase-9 (Cell Signaling no. 9508), rabbit anti-mouse caspase-1 (Santa Cruz, Dallas, TX, USA, no. 514), rat anti-mouse caspase-11 (Novus Biologicals, Littleton, CO, USA), rabbit anti-human FLIP (Santa Cruz no. 8346), mouse anti-cow COX IV (Abcam no. 14744), rabbit anti-human EEA1 (Abcam no. 2900), rabbit anti-human cytochrome $c$ (Abcam no. 133504), rabbit anti-human XIAP (Cell Signaling no. 2042), rabbit antihuman caspase-8 (Cell Signaling no. 9496), mouse anti-human caspase-8 (Cell Signaling no. 9746), rabbit anti-human VDAC (Cell Signaling no. 4866), rabbit antihuman caspase-1 (Santa Cruz, no. 622 antibody against N-terminal CARD domain), mouse anti-human FADD (Santa Cruz no. 271748), rabbit anti-human TRADD (Santa Cruz no. 7868), rabbit anti-human RIP-1 (Cell Signaling no. 3493), rabbit anti-human TRAF2 (Santa Cruz no. 877), mouse anti-human $\beta$-tubulin (clone D66, SigmaAldrich), and rabbit anti-mouse $\beta$-actin (Cell Signaling).

Annexin V labeling, MTT assay and incucyte zoom microscopy. Wild-type and NIrp3-/- TECs were grown to monolayer before treatment with $\mathrm{CHX}$ and TNF $\alpha$. Annexin V-FITC (BD Biosciences) and Sytox orange (Molecular Probes, Thermo Fisher Scientific, Waltham, MA, USA) was used to label apoptotic and necrotic TECs, respectively, and imaged over $24 \mathrm{~h}$ by fluorescent wide field microscope (Olympus, Center Valley, PA, USA). Annexin V and Sytox orange positivity was quantified by ImageJ analysis.

TECs were assessed for cell viability using the MTT assay (Invitrogen) as per the manufacturer's instructions. Tubular epithelial cells were grown to monolayer and treated with various reagents for $24 \mathrm{~h}$ in serum-free media. Cells were incubated with MTT reagent $(12 \mathrm{mM})$ for $4 \mathrm{~h}$ at $37^{\circ} \mathrm{C}$. Viable cells converted MTT to insoluble formazan crystals, which was solubilized by DMSO before quantification by spectrophotometer (Molecular Devices, Sunnyvale, CA, USA) at $540 \mathrm{nM}$. Cell viability was calculated for each treatment relative to untreated cells.

Tubular epithelial cells were grown to monolayer and induced to undergo apoptosis in serum-free media with or without incubation in 5 or $10 \mathrm{mM}$ of $\mathrm{KCl}$. Cells were treated with CellPlayer Kinetic Caspase 3/7 Reagent (Essen Bioscience, Ann Arbor, $\mathrm{MI}$, USA) to label apoptotic cells. Images were taken using an automated fluorescent microscope (Incucyte Zoom, Essen Bioscience) over a 24 -h time course at $37^{\circ} \mathrm{C}$. Apoptosis index was calculated by quantifying the number of apoptotic cells relative to the total number of cells per field and normalized as a fold change relative to time zero within each treatment.

Subcellular fractionations. HPTC subcellular fractionations were performed on untreated cells or treated with $\mathrm{TNF} \alpha / \mathrm{CHX}$. Cells were collected in $1 \mathrm{ml}$ of mannitol buffer (10 mM HEPES, $70 \mathrm{mM}$ Sucrose, $210 \mathrm{mM}$ D-Mannitol, $0.1 \mathrm{mM}$ EGTA, pH 7.4) containing protease inhibitor cocktail (Roche, Mississauga, $\mathrm{ON}$, Canada). Fifteen strokes through a $27-\mathrm{G}$ needle were performed to homogenize the cells, and the homogenate was spun at $320 \times g$ for $5 \mathrm{~min}$ to remove unbroken cells. The soluble fraction was spun at $8000 \times g$ for $15 \mathrm{~min}$ to collect crude mitochondrial fraction. The pellet containing mitochondria was washed in $1 \mathrm{ml}$ of PBS twice and re-suspended in $0.5 \mathrm{M}$ sucrose and gently layered on discontinuous sucrose gradient ( $30 \% \mathrm{w} / \mathrm{w} .40 \% \mathrm{w} / \mathrm{w}, 50 \% \mathrm{w} / \mathrm{w}, 60 \% \mathrm{w} / \mathrm{w}$ ) containing $1 \mathrm{mM}$ EDTA, $0.1 \% \mathrm{BSA}, 10 \mathrm{mM}$ Tris- $\mathrm{HCl}(\mathrm{pH} 7.5)$. After ultracentrifugation at $51000 \times g$ for $3 \mathrm{~h}$ at $4{ }^{\circ} \mathrm{C}$, intact mitochondrial band was collected and pelleted by additional centrifugation at $26000 \times \mathrm{g}$ for $30 \mathrm{~min}$ at $4^{\circ} \mathrm{C}$. To preserve oligomer form of ASC, $2 \mathrm{mM}$ of disuccinimidyl suberate was used to crosslink proteins. Mouse TEC subcellular fractionations were completed at $4{ }^{\circ} \mathrm{C}$ using the mitochondrial isolation kit for cultured cells from Thermo Fisher Scientific. Fractionations were carried out using the manufacturer's instructions.

Mitochondrial fractions were resuspended in $3 \times$ SDS sample buffer containing $0.1 \%$ Triton-X100 in preparation for immunoblotting. Samples were boiled for $5 \mathrm{~min}$ before loading into denaturing SDS gels for analysis. Cytosolic fractions were precipitated using chloroform and methanol and resuspended in an equivalent amount of sample buffer as the mitochondrial pellet. Briefly, four volumes of methanol were added to the cytosolic fraction and vortexed before the addition of one volume of chloroform. Samples were vortexed once again and three volumes of $\mathrm{H}_{2} \mathrm{O}$ were added followed by additional vortexing. Samples were spun at $15000 \times g$ for $2 \mathrm{~min}$, and the aqueous layer was removed. Four volumes of methanol were finally added, and the samples were vortexed and spun for a final time at $15000 \times g$ for $2 \mathrm{~min}$. The remaining liquid was completely removed, and the resulting precipitate was resuspended in sample buffer. Fractions were characterized using immunoblotting and antibodies against tubulin, EEA1 (cytosolic), VDAC and COX IV (mitochondrial).

RNA interference. HPTC were trypsinized and one million cells were nucleofected with $30 \mathrm{pmol}$ of non-targeting (5'-UAGCGACUAAACACAUCAA-3') or SMARTpool small interfering RNAs of FADD (with the following sequences: 5'-CAGCAUUUAACGUCAUAUG-3'; 5'-UGCAGCAUUUAACGUCAUA-3'; $5^{\prime}$-GUGC AGCAUUUAACGUCAU-3'; 5'-GAACUCAAGCUGCGUUUAU-3') or TRADD (with the following sequences: $5^{\prime}$-GGAGGAUGCGCUGCGAAAU-3'; 5'-GCGAGGGACU GUACGAGCA-3'; 5'-GGGUCAGCCUGUAGUGAAU-3'; 5'-GGACGAGGAGCGCU GUUUG-3') (Dharmacon, Lafayette, CO, USA) using the Nucleofection Technology (Amaxa, London, UK) according to the manufacturer's protocols. Transfected cells were seeded in a six-well plate $\left(0.5 \times 10^{6} /\right.$ well $)$ and incubated for $48 \mathrm{~h}$ before treatment. Efficacy of gene knockdown was confirmed by immunoblotting.

Immunofluorescence microscopy. HPTCs were grown to $70 \%$ confluency on sterile collagen-coated coverslips. Cells were stimulated with TNF $\alpha$ $(10 \mathrm{ng} / \mathrm{ml})$ and $\mathrm{CHX}(25 \mu \mathrm{g} / \mathrm{ml})$ or mock treated in serum-free media for $24 \mathrm{~h}$ prior to fixation, and cells were incubated with $300 \mu \mathrm{l} 1 \times$ FAM-LETD-fmk (FLICA-caspase-8, Immunochemistry Inc., Bloomington, MN, USA) or FAM-YVADfmk (FLICA-caspase-1) or Mitotracker red (100 nM, Molecular Probes, ThermoFisher Scientific) for $1 \mathrm{~h}$. FLICA-treated cells were washed in wash buffer according to the manufacturer's protocol. Cells were then washed in PBS and fixed in $4 \%$ paraformaldehyde followed by incubation with $\mathrm{NH}_{4} \mathrm{Cl}(50 \mu \mathrm{M})$ for 10 min to reduce auto-fluorescence and permeabilization with $0.1 \%$ Triton X-100 for $5 \mathrm{~min}$. Cells were blocked in $3 \%$ BSA for 30 min at room temperature and then incubated with primary antibodies (1:100) in blocking solution for $1 \mathrm{~h}$ at room temperature. Antibodies used in the experiments are mouse anti-human NLRP3 (Cryo-2, Adipogen), rabbit antihuman ASC (Adipogen), mouse anti-human E-Cadherin (BD Biosciences no. 610181), rabbit anti-human LAMP1 (Abcam no. 24170), mouse anti-human FADD (Santa Cruz), rabbit anti-human TRADD (Santa Cruz) and rabbit anti-human GM130 (Abcam no. 52649). Following sequential washes in PBS, cells were incubated with secondary fluorescent antibodies (1:600, Alexa Fluor, Thermo-Fisher Scientific) in blocking solution for $1 \mathrm{~h}$ at room temperature. Coverslips were mounted onto slides in ProlongGold antifade reagent containing 4',6-diamidino-2phenylindole (DAPI, Molecular Probes, Thermo-Fisher Scientific). For in vivo studies, immunofluorescence microscopy was performed on the kidneys from mice 14 days after UUO. Kidneys were removed and prepared for immunoblotting or histology using 10\% formalin fixation. Paraffin-embedded kidney tissue sections were deparaffinized, blocked and stained with E-Cadherin (BD Biosciences), ASC (Adipogen) and cleaved caspase-3 antibodies (Cell Signaling) using standard staining protocols. Confocal microscopy was performed on an Olympus IX-70 microscope with the Fluoview1000 system software (Center Valley, PA, USA).

Enteroid cultures used for immunofluorescent microscopy were fixed overnight with $10 \%$ formalin, $1 \mathrm{~h}$ posttreatment with TNF $\alpha / \mathrm{CHX}$. Following formalin fixation, enteroids were washed in PBS, resuspended in $3 \%$ low-melting point agarose, embedded in paraffin and sectioned onto microscope slides. Sections were deparaffinized with xylene and rehydrated in 100, 95 and $75 \%$ ethanol, followed by deionized water. Antigen retrieval was performed by boiling in sodium citrate buffer for $30 \mathrm{~min}$. Sections were blocked with goat serum for $1 \mathrm{~h}$ at RT and treated with antiNLRP3 and anti-ASC primary antibodies $(1: 100)$ in blocking buffer overnight at $4{ }^{\circ} \mathrm{C}$. Following two PBS washes, sections were incubated with appropriate secondary antibodies (1:1000, Thermo-Fisher Scientific) for $1 \mathrm{~h}$ at RT and washed twice in PBS and once in $\mathrm{H}_{2} \mathrm{O}$. Coverslips were mounted onto slides in ProlongGold antifade reagent containing DAPI (Molecular Probes, Thermo-Fisher Scientific), and confocal microscopy was performed with a Leica SP5 Microscope with the Leica application suite software (Buffalo Grove, IL, USA).

Statistical analysis and ethics. All studies using mice or human tissues were approved by the Animal Care Committee and the Conjoint Health Research 
Ethics Board at the University of Calgary, respectively. Except where indicated, all experiments were performed at least three independent times. GraphPad Instat software (La Jolla, CA, USA) was used to perform all statistical analyses. Data were expressed as mean \pm S.D. or S.E.M. as indicated. Results were analyzed for statistical variance using an unpaired Student's $t$-test or ANOVA where appropriate. Results at $P<0.05$ were considered statistically significant.

\section{Conflict of Interest}

The authors declare no conflict of interest.

Acknowledgements. This work was supported by operating grants from the Canadian Institutes for Health Research (to BAV and DAM), the Kidney Foundation of Canada (to DAM) and the Crohn's and Colitis Canada (CCC) (to BAV). Research was also supported by the Canadian National Transplantation Research Program (CNTRP) and the CIHR Inflammation in Chronic Disease Signature Initiative (to DAM). We thank Sharon A Clark for her technical support as well as the infrastructure and technical support provided by the Live Cell Imaging Facility at the Snyder Institute for Chronic Diseases. DAM holds a Tier II Canada Research Chair and a Clinical Senior Scholar award from Alberta Innovates Health Solutions (AIHS). BAV holds the Children with Intestinal and Liver Disorders (CH.I.L.D.) Foundation Research Chair in Pediatric Gastroenterology. PLB holds a Clinical Senior Scholar award from AlHS. JMP and AL are supported by Beverley Phillips Trainee Awards from the Snyder Institute for Chronic Disease, University of Calgary. MS is supported by a fellowship from the Michael Smith Foundation for Health Research (MSFHR), while VM is supported by a joint fellowship from the MSFHR and CCC.

1. Sutterwala FS, Haasken S, Cassel SL. Mechanism of NLRP3 inflammasome activation. Ann NY Acad Sci 2014; 1319: 82-95.

2. Anders HJ, Muruve DA. The inflammasomes in kidney disease. J Am Soc Nephrol 2011; 22: 1007-1018.

3. Knodler LA, Crowley SM, Sham HP, Yang H, Wrande M, Ma C et al. Noncanonical inflammasome activation of caspase-4/caspase-11 mediates epithelial defenses against enteric bacterial pathogens. Cell Host Microbe 2014; 16: 249-256.

4. Sagulenko V, Thygesen SJ, Sester DP, Idris A, Cridland JA, Vajjhala PR et al. AIM2 and NLRP3 inflammasomes activate both apoptotic and pyroptotic death pathways via ASC. Cell Death Differ 2013; 20: 1149-1160.

5. Kayagaki N, Warming S, Lamkanfi M, Vande Walle L, Louie S, Dong J et al. Non-canonical inflammasome activation targets caspase-11. Nature 2011; 479: 117-121.

6. Kantari C, Walczak H. Caspase-8 and bid: caught in the act between death receptors and mitochondria. Biochim Biophys Acta 2011; 1813: 558-563.

7. Jost PJ, Grabow S, Gray D, McKenzie MD, Nachbur U, Huang DC et al. XIAP discriminates between type I and type II FAS-induced apoptosis. Nature 2009; 460: 1035-1039.

8. Scaffidi C, Schmitz I, Zha J, Korsmeyer SJ, Krammer PH, Peter ME. Differential modulation of apoptosis sensitivity in CD95 type I and type II cells. J Biol Chem 1999; 274: 22532-22538.

9. Gonzalvez F, Schug ZT, Houtkooper RH, MacKenzie ED, Brooks DG, Wanders RJ et al. Cardiolipin provides an essential activating platform for caspase-8 on mitochondria. J Cell Biol 2008; 183: 681-696.

10. Li H, Zhu H, Xu CJ, Yuan J. Cleavage of BID by caspase 8 mediates the mitochondrial damage in the Fas pathway of apoptosis. Cell 1998; 94: 491-501.

11. Du C, Fang M, Li Y, Li L, Wang X. Smac, a mitochondrial protein that promotes cytochrome c-dependent caspase activation by eliminating IAP inhibition. Cell 2000; 102: 33-42.

12. Pierini R, Juruj $C$, Perret $M$, Jones $C L$, Mangeot $P$, Weiss DS et al. AIM2/ASC triggers caspase-8-dependent apoptosis in Francisella-infected caspase-1-deficient macrophages. Cell Death Differ 2012; 19: 1709-1721.

13. Man SM, Hopkins LJ, Nugent E, Cox S, Gluck IM, Tourlomousis $P$ et al. Inflammasome activation causes dual recruitment of NLRC4 and NLRP3 to the same macromolecular complex. Proc Natl Acad Sci USA 2014; 111: 7403-7408.

14. Man SM, Tourlomousis P, Hopkins L, Monie TP, Fitzgerald KA, Bryant CE. Salmonella infection induces recruitment of Caspase- 8 to the inflammasome to modulate IL-1beta production. J Immunol 2013; 191: 5239-5246.

15. Karki R, Man SM, Malireddi RK, Gurung P, Vogel P, Lamkanfi M et al. Concerted activation of the AIM2 and NLRP3 inflammasomes orchestrates host protection against aspergillus infection. Cell Host Microbe 2015; 17: 357-368.

16. Ganesan S, Rathinam VA, Bossaller L, Army K, Kaiser WJ, Mocarski ES et al. Caspase-8 modulates dectin-1 and complement receptor 3-driven IL-1beta production in response to beta-glucans and the fungal pathogen, Candida albicans. J Immunol 2014; 193: 2519-2530.
17. Gringhuis SI, Kaptein TM, Wevers BA, Theelen B, van der Vlist M, Boekhout T et al. Dectin-1 is an extracellular pathogen sensor for the induction and processing of IL-1beta via a noncanonical caspase-8 inflammasome. Nat Immunol 2012; 13: 246-254.

18. Grgic I, Campanholle G, Bijol V, Wang C, Sabbisetti VS, Ichimura T et al. Targeted proximal tubule injury triggers interstitial fibrosis and glomerulosclerosis. Kidney Int 2012; 82: $172-183$.

19. Hirota SA, Ng J, Lueng A, Khajah M, Parhar K, Li Y et al. NLRP3 inflammasome plays a key role in the regulation of intestinal homeostasis. Inflamm Bowel Dis 2011; 17: 1359-1372.

20. Vilaysane A, Chun J, Seamone ME, Wang W, Chin R, Hirota S et al. The NLRP3 inflammasome promotes renal inflammation and contributes to CKD. J Am Soc Nephrol 2010; 21: 1732-1744.

21. Wang W, Wang X, Chun J, Vilaysane A, Clark S, French G et al. Inflammasome-independent NLRP3 augments TGF-beta signaling in kidney epithelium. J Immunol 2013; 190: 1239-1249.

22. Bakker PJ, Butter LM, Claessen N, Teske GJ, Sutterwala FS, Florquin S et al. A tissuespecific role for NIrp3 in tubular epithelial repair after renal ischemia/reperfusion. Am J Pathol 2014; 184: 2013-2022.

23. Shigeoka AA, Mueller JL, Kambo A, Mathison JC, King AJ, Hall WF et al. An inflammasomeindependent role for epithelial-expressed NIrp3 in renal ischemia-reperfusion injury. $\mathrm{J}$ Immunol 2010; 185: 6277-6285.

24. Wang L, Du F, Wang X. TNF-alpha induces two distinct caspase-8 activation pathways. Cell 2008; 133: 693-703.

25. Benetatos CA, Mitsuuchi Y, Burns JM, Neiman EM, Condon SM, Yu G et al. Birinapant (TL32711), a bivalent SMAC mimetic, targets TRAF2-associated clAPs, abrogates TNF-induced NF-kappaB activation, and is active in patient-derived xenograft models. Mol Cancer Ther 2014; 13: 867-879.

26. Bossaller L, Chiang PI, Schmidt-Lauber C, Ganesan S, Kaiser WJ, Rathinam VA et al. Cutting edge: FAS (CD95) mediates noncanonical IL-1beta and IL-18 maturation via caspase-8 in an RIP3-independent manner. J Immunol 2012; 189: 5508-5512.

27. Bracey NA, Gershkovich B, Chun J, Vilaysane A, Meijndert HC, Wright JR Jr. et al. Mitochondrial NLRP3 protein induces reactive oxygen species to promote Smad protein signaling and fibrosis independent from the inflammasome. J Biol Chem 2014; 289 : 19571-19584.

28. Zhou R, Yazdi AS, Menu P, Tschopp J. A role for mitochondria in NLRP3 inflammasome activation. Nature 2011; 469: 221-225.

29. Iyer $\mathrm{SS}, \mathrm{He} Q$, Janczy JR, Elliott El, Zhong Z, Olivier AK et al. Mitochondrial cardiolipin is required for NIrp3 inflammasome activation. Immunity 2013; 39: 311-323.

30. Martin SJ, Lennon SV, Bonham AM, Cotter TG. Induction of apoptosis (programmed cell death) in human leukemic HL-60 cells by inhibition of RNA or protein synthesis. J Immunol 1990; 145: 1859-1867.

31. Tang D, Lahti JM, Grenet J, Kidd VJ. Cycloheximide-induced T-cell death is mediated by a Fas-associated death domain-dependent mechanism. J Biol Chem 1999; 274: 7245-7252.

32. Petrilli V, Papin S, Dostert C, Mayor A, Martinon F, Tschopp J. Activation of the NALP3 inflammasome is triggered by low intracellular potassium concentration. Cell Death Differ 2007; 14: 1583-1589.

33. Sato T, Vries RG, Snippert HJ, van de Wetering M, Barker N, Stange DE et al. Single Lgr5 stem cells build crypt-villus structures in vitro without a mesenchymal niche. Nature 2009; 459: 262-265.

34. Milovic-Holm K, Krieghoff E, Jensen K, Will H, Hofmann TG. FLASH links the CD95 signaling pathway to the cell nucleus and nuclear bodies. EMBO J 2007; 26: 391-401.

35. Stegh AH, Barnhart BC, Volkland J, Algeciras-Schimnich A, Ke N, Reed JC et al. Inactivation of caspase- 8 on mitochondria of Bcl-xL-expressing MCF7-Fas cells: role for the bifunctional apoptosis regulator protein. J Biol Chem 2002; 277: 4351-4360.

36. El Maadidi S, Faletti L, Berg B, Wenzl C, Wieland K, Chen ZJ et al. A novel mitochondrial MAVS/Caspase-8 platform links RNA virus-induced innate antiviral signaling to Bax/Bakindependent apoptosis. J Immunol 2014; 192: 1171-1183.

37. Park S, Juliana C, Hong S, Datta P, Hwang I, Fernandes-Alnemri T et al. The mitochondrial antiviral protein MAVS associates with NLRP3 and regulates its inflammasome activity. J Immunol 2013; 191: 4358-4366.

38. Subramanian N, Natarajan K, Clatworthy MR, Wang Z, Germain RN. The adaptor MAVS promotes NLRP3 mitochondrial localization and inflammasome activation. Cell 2013; 153: 348-361.

39. Martinon F, Petrilli V, Mayor A, Tardivel A, Tschopp J. Gout-associated uric acid crystals activate the NALP3 inflammasome. Nature 2006; 440: 237-241.

40. Mariathasan S, Newton K, Monack DM, Vucic D, French DM, Lee WP et al. Differential activation of the inflammasome by caspase-1 adaptors ASC and Ipaf. Nature 2004; 430 : 213-218.

41. Kuida K, Lippke JA, Ku G, Harding MW, Livingston DJ, Su MS et al. Altered cytokine export and apoptosis in mice deficient in interleukin-1 beta converting enzyme. Science 1995; 267: 2000-2003.

42. Sato T, Stange DE, Ferrante M, Vries RG, Van Es JH, Van den Brink S et al. Long-term expansion of epithelial organoids from human colon, adenoma, adenocarcinoma, and Barrett's epithelium. Gastroenterology 2011; 141: 1762-1772. 